Article

\title{
Experimental West Nile Virus Infection in Rabbits: An Alternative Model for Studying Induction of Disease and Virus Control
}

Willy W. Suen ${ }^{1}$, Muhammad J. Uddin ${ }^{1}$, Wenqi Wang ${ }^{1}$, Vienna Brown ${ }^{2}$, Danielle R. Adney ${ }^{3}$, Nicole Broad ${ }^{4}$, Natalie A. Prow ${ }^{4,5}$, Richard A. Bowen ${ }^{2}$, Roy A. Hall ${ }^{5,6}$ and

Helle Bielefeldt-Ohmann ${ }^{1,5}$, *

1 School of Veterinary Science, University of Queensland, Gatton, QLD 4343, Australia; E-Mails: w.suen@uq.edu.au (W.W.S.); m.uddin2@uq.edu.au (M.J.U.);w.wang3@uq.edu.au (W.W.)

2 Department of Biomedical Sciences, Colorado State University, Fort Collins, CO 80523, USA; E-Mails: vienna.brown@colostate.edu (V.B.); rbowen@rams.colostate.edu (R.A.B.)

3 Department of Microbiology, Immunology and Pathology, Colorado State University, Fort Collins, CO 80523, USA; E-Mail: danielle.adney@colostate.edu

4 QIMR Berghofer Medical Research Institute, Brisbane, QLD 4006, Australia;

E-Mails: nicole.broad@qimrberghofer.edu.au (N.B.); Natalie.Prow@qimrberghofer.edu.au (N.A.P.)

5 Australian Infectious Diseases Research Centre, University of Queensland, St Lucia, QLD 4072, Australia; E-Mail: roy.hall@uq.edu.au

6 School of Chemistry and Molecular Bioscience, University of Queensland, St Lucia, QLD 4072, Australia

* Author to whom correspondence should be addressed; E-Mail: h.bielefeldtohmann1@uq.edu.au; Tel.: +61-7-5460-1854.

Academic Editor: Thomas E. Morrison

Received: 15 May 2015 / Accepted: 6 July 2015 / Published: 14 July 2015

\begin{abstract}
The economic impact of non-lethal human and equine West Nile virus (WNV) disease is substantial, since it is the most common presentation of the infection. Experimental infection with virulent WNV strains in the mouse and hamster models frequently results in severe neural infection and moderate to high mortality, both of which are not representative features of most human and equine infections. We have established a rabbit model for investigating pathogenesis and immune response of non-lethal WNV infection. Two species of rabbits, New Zealand White (Oryctolagus cuniculus) and North American cottontail (Sylvilagus sp.), were experimentally infected with virulent WNV and Murray Valley
\end{abstract}


encephalitis virus strains. Infected rabbits exhibited a consistently resistant phenotype, with evidence of low viremia, minimal-absent neural infection, mild-moderate neuropathology, and the lack of mortality, even though productive virus replication occurred in the draining lymph node. The kinetics of anti-WNV neutralizing antibody response was comparable to that commonly seen in infected horses and humans. This may be explained by the early IFN $\alpha / \beta$ and/or $\gamma$ response evident in the draining popliteal lymph node. Given this similarity to the human and equine disease, immunocompetent rabbits are, therefore, a valuable animal model for investigating various aspects of non-lethal WNV infections.

Keywords: West Nile virus; animal models; pathogenesis; rabbit

\section{Introduction}

West Nile virus (WNV) is an important re-emerging neurotropic arbovirus, that continues to cause severe outbreaks world-wide. However, the majority of WNV infections in humans and horses, the incidental hosts of the transmission cycle, is non-lethal and subclinical [1-5]. The reported mortality rate in humans and horses from neuroinvasive WNV disease is $<1 \%$ and $\sim 10 \%$, respectively, of those infected [1-5]. But the economic burden of non-lethal WNV disease is substantial. Nolan et al. has reported an estimated cost of $\$ 42$ million for non-lethal West Nile fever (WNF) human cases in Texas alone during the period spanning 2002 to 2011 [6]. An estimated further $\$ 70$ million was reported for West Nile neuroinvasive disease (WNND) cases in the same period [6]. Given the low case-fatality rate of $\sim 9 \%$ of WNND in humans, the majority of the $\$ 70$ million would have been attributed to non-lethal neurological WNV cases [3]. This highlights the significance in investigating the mechanisms of non-lethal WNV disease.

Currently, the mouse and hamster are the main small animal models for investigating WNV-associated pathogenesis and host immune response in humans and horses [7-9]. While these rodent models typically produce severe encephalitis after virulent WNV infection, the level of central nervous system (CNS) infection in these small animal models often is too severe to be reflective of most human and equine disease [7,8]. Minimal levels of virus replication take place in the CNS of most human and equine infection, unless the individuals are immunocompromized [10-13]. This important difference suggests that the neuropathogenesis of WNV in immunocompetent rodents poorly reflects what happens in immunocompetent humans and horses. In addition, the relatively higher susceptibility of the mouse model means that investigations into mechanisms of virus control will often require the use of attenuated WNV strains $[14,15]$. But whether these mechanisms reflect how most healthy humans and horses naturally overcome virulent WNV infection is questionable.

Given these limitations associated with the current rodent models, there is a need to test and establish alternative small animal infection models to study natural mechanisms of virus control and induction of WNV disease. While non-human primate (NHP) and direct horse infection models can be used to better understand WNV pathogenesis, the cost and logistics are greatly limiting.

The present study established an alternative small animal model in laboratory New Zealand White rabbits (NZWR; Oryctolagus cuniculus) for investigating WNV-induced disease and host immune 
response. Comparative experimental infection was conducted in wild-caught North American cottontail rabbits (CTR; Sylvilagus sp.). A contemporary Australian equine-pathogenic outbreak strain, WNVNSW2011, was used as the main strain of interest as it has been shown to be highly virulent in the weanling CD1 Swiss mouse model and of intermediate virulence in the young adult model [16]. A 2012 North American WNV isolate (WNVTX8667) and the Murray Valley encephalitis virus (MVEV) prototype strain, $\mathrm{MVE}_{1-51}$, were used as virulent flavivirus controls.

The resultant mild clinical course without mortality, low viremia, minimal to absent CNS infection, mild to moderate neuropathology, and fast neutralizing antibody response in WNV-infected rabbits mimic closely the features of most human and equine WNV infections. Based on the virus kinetics, the robust type I and/or II interferon (IFN-I and -II) responses detected in the draining popliteal lymph node (PLN) and brain appeared to be important as first defence against early virus replication. Neutralizing antibodies then additionally restricted and resolved WNV infection. This consistently resistant phenotype in rabbits against virulent WNV infection suggests that rabbits are a superior model for studying resolution of virulent WNV infections compared to the relatively more susceptible mouse model. The rabbit model presented here will be valuable for identifying novel prognostic indicators, and for developing new therapeutics and prevention strategies. The model will also be amenable for studies of the effect of immunosuppression or co-infection on the outcome of WNV-infection, which are well-known risk factors for development of severe neurological disease in humans and horses [11,17].

\section{Results}

\subsection{Subclinical and Non-Lethal Infection}

A total of 63 rabbits were experimentally infected with outbreak strains of flavivirus originally

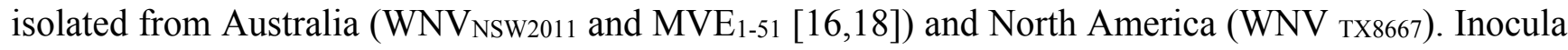
were administered intradermally in the left hind footpad at the dose of $10^{5} \mathrm{TCID}_{50}$ for NZWRs infected with WNV $\mathrm{NSW}_{2011}$ and MVE1-51, or $10^{5}$ PFU for CTRs infected with WNV $\mathrm{NSW}_{2011}$ and WNV $\mathrm{WX}_{8667 .}$ Table 1 summarizes the assignment of rabbits into each challenge group. None of the infected rabbits succumbed to the virus challenge. The only clinical sign of illness was a mild to moderate fever evident

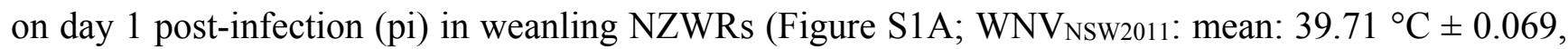
$n=24$; MVE $1-51$ : mean: $39.92{ }^{\circ} \mathrm{C} \pm 0.13, n=21$; Control: mean: $39.17{ }^{\circ} \mathrm{C} \pm 0.076, n=6$ ). No febrile response was detected in any of the infected adult NZWRs and CTRs (Figure S1B). Enlargement of the draining and contralateral PLNs was detected on palpation during clinical examination of the NZWRs (Figure S1C-F). However, there were no obvious signs of neurological deficit or dysfunction, nor were there any significant changes in weight of the infected rabbits. 
Table 1. Assignment and number of rabbits per challenge group

\begin{tabular}{|c|c|c|c|c|c|c|c|c|}
\hline \multirow{3}{*}{$\begin{array}{c}\text { Rabbit Species } \\
\text { Age } \\
\text { Inoculum }\end{array}$} & \multicolumn{5}{|c|}{ New Zealand White Rabbit (NZWR) } & \multirow{2}{*}{\multicolumn{3}{|c|}{$\begin{array}{c}\text { Cottontail Rabbit (CTR) } \\
\text { Mixed Age } \\
(\sim 250-900 \text { g) }\end{array}$}} \\
\hline & \multicolumn{3}{|c|}{$\begin{array}{c}\text { Weanlings } \\
(4-5 \text { Weeks Old, } \sim 500-700 \mathrm{~g})\end{array}$} & \multicolumn{2}{|c|}{$\begin{array}{c}\text { Adults } \\
\text { (>3 Months Old, } \sim 3000 \text { g) }\end{array}$} & & & \\
\hline & $\mathrm{WNV}_{\mathrm{NSW} 2011}$ & $\mathrm{MVE}_{1-51}$ & Sham & $\mathrm{WNV}_{\mathrm{NSW} 2011}$ & $\mathrm{MVE}_{1-51}$ & WNV NSW2011 & $\mathrm{WNV}_{\mathrm{TX} 8667}$ & Sham \\
\hline Termination day (pi) & Group 1 & Group 2 & Control & Group 3 & Group 4 & Group 5 & Group 6 & Control \\
\hline 3 & 3 & 3 & $\mathrm{~N} / \mathrm{D}$ & $\mathrm{N} / \mathrm{D}$ & $\mathrm{N} / \mathrm{D}$ & 3 & 3 & 1 \\
\hline 7 & 9 & 6 & 3 & 3 & 3 & 3 & 3 & 1 \\
\hline 12 & 6 & 6 & $\mathrm{~N} / \mathrm{D}$ & $\mathrm{N} / \mathrm{D}$ & $\mathrm{N} / \mathrm{D}$ & $\mathrm{N} / \mathrm{D}$ & $\mathrm{N} / \mathrm{D}$ & $\mathrm{N} / \mathrm{D}$ \\
\hline 18 & 6 & 6 & 3 & $\mathrm{~N} / \mathrm{D}$ & $\mathrm{N} / \mathrm{D}$ & $\mathrm{N} / \mathrm{D}$ & $\mathrm{N} / \mathrm{D}$ & $\mathrm{N} / \mathrm{D}$ \\
\hline Totals & 24 & 21 & 6 & 3 & 3 & 6 & 6 & 2 \\
\hline
\end{tabular}

N/D: not done.

\subsection{Neuropathology}

The neuropathology observed in rabbits infected with $\mathrm{WNV}_{\mathrm{NSW} 2011}$, WNVTX8667, and $\mathrm{MVE}_{1-51}$ consisted of mild to moderate mononuclear leukocytic, and occasionally heterophilic, infiltration in the $\mathrm{CNS}$, with the latter two strains producing the most frequent and severe lesions (Figure 1A-C). There was a trend for weanling NZWRs to develop more severe neuropathology than adults (Table 2). Table 3 summarizes the kinetics of neuropathology observed in the different virus challenge groups at days 3, 7, 12, and 18 pi. Most severe and extensive leukocyte infiltration in the CNS was observed on day 7 pi for both weanling NZWR groups (Table 3). However, moderate neuropathology was still evident on day 12 pi in brains of weanling NZWRs infected with MVE1-51. The incidence of MVE151-induced neuropathology in weanling NZWRs on day 7 was significantly higher than those of the sham-inoculation control group $(p=0.0022)$, of adult NZWRs infected with $\operatorname{MVE}_{1-51}(p=0.0333)$ and of weanling NZWRs infected with $\mathrm{WNV}_{\mathrm{NSW}} 2011(p=0.0108)$. Mild to moderate perivascular cuffing, extensive gliosis, and occasional neuronal degeneration with neuronophagia were evident in brains of weanling NZWRs infected with MVE1-51 at all time-points beyond day 7 pi. This contrasts with the relatively milder lesions seen in weanling NZWRs infected with WNVNsw2011 (Figure 1A). Neuropathology seen in the WNVNSW2011-infected CTRs was comparable to that in weanling NZWRs infected with the same strain (Table 3). CTRs infected with WNVTX8667 showed more extensive and severe lesions in the CNS than ones infected with WNVNSw2011, though there was no evidence of neuronal degeneration in the former group (Figure 1C). 


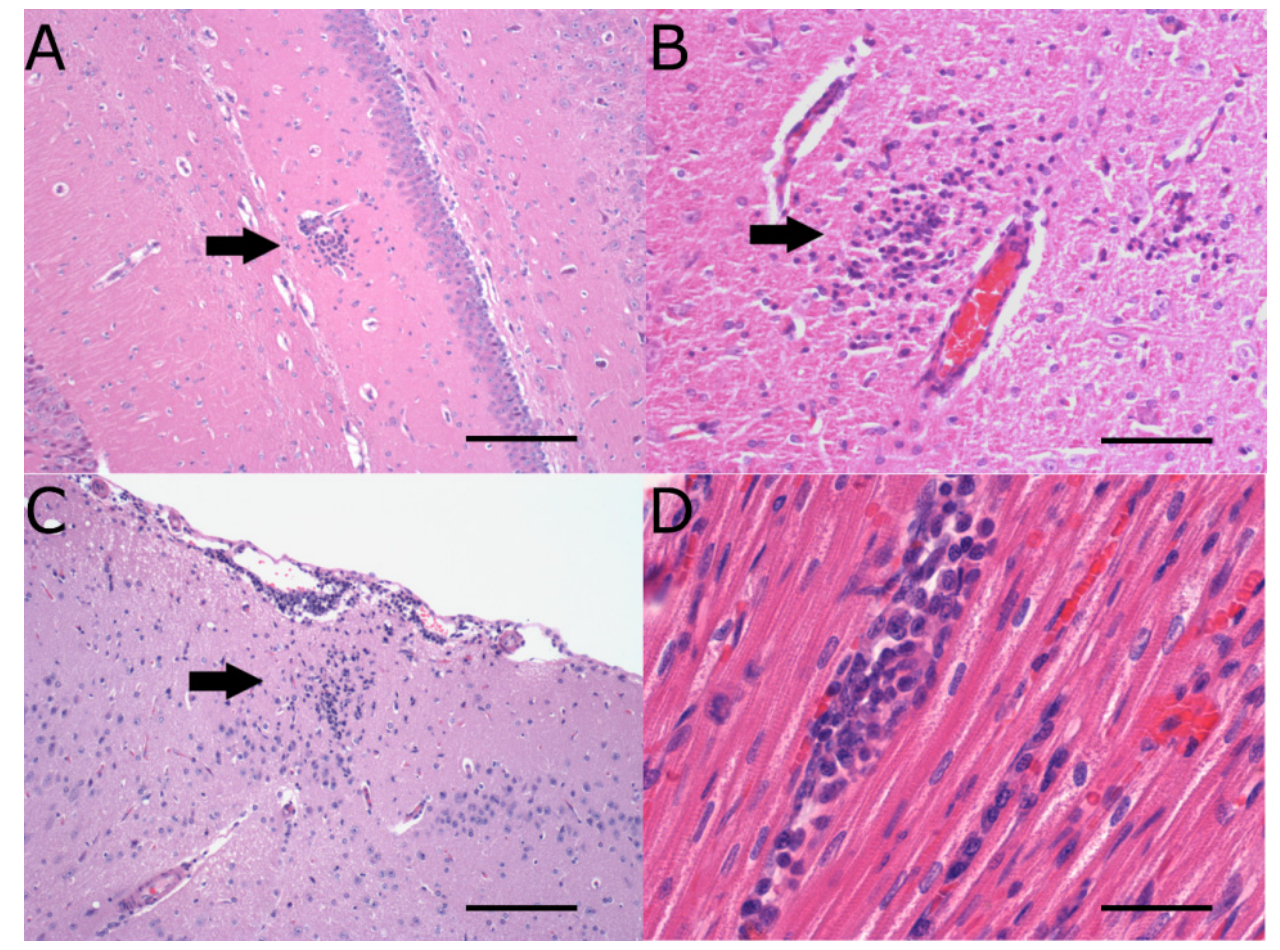

Figure 1. Histopathology of the central nervous system (CNS) and heart. Mononuclear leukocytic infiltrate (black arrow) in the neuropil of brains from NZWRs infected with WNVNSW2011 (A), MVE1-51 (B) and CTRs- infected with WNVTX8667 (C) on day 7 pi. Mononuclear leukocytic infiltrate in myocardium of a NZWR infected with WNVNSW2011 on day 7 pi (D). Panels (A-D) were stained with H\&E stain. Magnifications: (A) 10×; (B) 20×, (C) $10 \times$, and (D) 40×. Scale bar in each panel represents $150 \mu \mathrm{m}(\mathbf{A}, \mathbf{C}), 100 \mu \mathrm{m}(\mathbf{B})$, and 30 $\mu \mathrm{m}(\mathrm{D})$.

Table 2. Comparison of the peak neuropathology scores in NZWRs on day 7 pi.

\begin{tabular}{lccc}
\hline \multicolumn{1}{c}{ Neuropathology } & Virus strain & Weanling & Adults \\
\hline \multirow{2}{*}{ Meningitis (Brain) } & WNV $_{\text {NSW2011 }}$ & 2 & 1 \\
& MVE $_{1-51}$ & 2 & 1 \\
\hline \multirow{2}{*}{ Encephalitis (Brain) } & WNV $_{\text {NSw2011 }}$ & 2 & 1 \\
& MVE $_{1-51}$ & 3 & 1 \\
\multirow{2}{*}{ Meningitis (Olfactory bulbs) } & WNV $_{\text {NSW2011 }}$ & 2 & 1 \\
\hline \multirow{2}{*}{ Encephalitis (Olfactory bulbs) } & MVE $_{1-51}$ & 2 & 1 \\
\hline \multirow{2}{*}{ Spinal Meningitis } & WNV $_{\text {NSW2011 }}$ & 2 & 0 \\
\hline \multirow{2}{*}{ Myelitis } & MVE $_{1-51}$ & 2 & 0 \\
\hline
\end{tabular}

Neuropathology was scored using a 5-tiered system, with 0 indicating normal and 5 indicating severe and diffuse lesions. This scoring system takes into account of the severity and extensiveness of the lesions (see Table 4). 
Table 3. Comparison of neuropathology kinetics.

\begin{tabular}{|c|c|c|c|c|}
\hline & Day 3 pi & Day 7 pi & Day 12 pi & Day 18 pi \\
\hline $\begin{array}{l}\text { WNV }_{\text {NSW2011 }} \\
\text { (weanling } \\
\text { NZWRs) }\end{array}$ & $\begin{array}{l}\mathrm{Mn} \text { and rare htl near CVO } \\
\text { and neuropil of brain } \\
\text { (peak score }=1, n=2 / 3 \text { ) }\end{array}$ & $\begin{array}{l}\text { Mn in meninges, neuropil of brain, } \\
\text { olfactory bulbs, spinal cord, perineurium } \\
\text { and/or nerve fibres of spinal nerves in } \\
\text { cauda equine (peak score }=2, n=4 / 9 \text { ) }\end{array}$ & $\begin{array}{l}\text { Mn in meninges, neuropil } \\
\text { of brain and cranial cervical } \\
\text { spinal cord (peak score }=1 \text {, } \\
\quad n=4 / 6)\end{array}$ & $\begin{array}{l}\text { Mn in meninges, neuropil } \\
\text { of brain near CVO and } \\
\text { cranial cervical spinal cord } \\
\text { (peak score }=1, n=2 / 6 \text { ) }\end{array}$ \\
\hline $\begin{array}{l}\text { MVE }_{1-51} \\
\text { (weanling } \\
\text { NZWRs) }\end{array}$ & No pathology $(n=0 / 3)$ & $\begin{array}{l}\text { Mn with occasional htl in meninges, neuropil } \\
\text { of brain (extensive with neuronophagia), } \\
\text { olfactory bulbs, spinal cord, perineurium } \\
\text { of spinal nerves and/or dorsal root ganglion in } \\
\text { cauda equine (peak score }=3, n=6 / 6 \text { ) }\end{array}$ & $\begin{array}{l}\text { Mn, with occasional htl } \\
\text { in meninges, neuropil of } \\
\text { brain (extensive) with } \\
\text { neuronophagia } \\
\text { (peak score }=3, n=4 / 6 \text { ) }\end{array}$ & $\begin{array}{l}\text { Mn,with occasional htl } \\
\text { in meninges, neuropil of } \\
\text { brain (extensive) })^{+} \text {(peak } \\
\text { score }=2, n=2 / 6 \text { ) }\end{array}$ \\
\hline $\begin{array}{l}\mathrm{WNV}_{\mathrm{NSW} 2011} \\
\text { (CTRs) }\end{array}$ & No pathology $(n=0 / 3)$ & $\begin{array}{l}\text { Mn in meninges, neuropil of brain and spinal } \\
\text { cord (peak score }=2, n=1 / 3 \text { ) }\end{array}$ & $\mathrm{N} / \mathrm{D}$ & $\mathrm{N} / \mathrm{D}$ \\
\hline $\begin{array}{c}\mathrm{WNV}_{\mathrm{TX} 8667} \\
(\mathrm{CTRs})\end{array}$ & No pathology $(n=0 / 3)$ & $\begin{array}{l}\text { Mn in meninges and neuropil of brain } \\
\text { (extensive; peak score }=3, \mathrm{n} 2 / 3 \text { ) }\end{array}$ & $\mathrm{N} / \mathrm{D}$ & $\mathrm{N} / \mathrm{D}$ \\
\hline
\end{tabular}

Mn, mononuclear leukocytes; Htl, heterophils; CVO, circumventricular organ; peak score, peak neuropathology score in the CNS (out of 5). ${ }^{+}$Spinal cord and olfactory bulbs were not examined, N/D: not done. 
In addition to the CNS, histopathology of the peripheral nervous system was analyzed in a subset of animals. There was no frank lesion in the sciatic nerve ipsilateral to the footpad inoculation, except for one CTR infected with WNVNSW2011 and sacrificed on day 3 pi. However, mild to moderate peri- and/ or epineuritis was commonly observed in the ipsilateral nerve on day 3 pi and the contralateral nerve on day 3 and 7 pi (Table S3).

Immunolabeling for leukocyte markers established that approximately half of the CNS-infiltrating leukocytes for rabbits infected with $\mathrm{WNV}_{\mathrm{NSW} 2011}$ and $\mathrm{MVE}_{1-51}$ were $\mathrm{CD} 3$ positive $\mathrm{T}$ lymphocytes (Figure 2A,B). No signal was detected when sections were labeled for the myelomonocytic marker MAC387. However, this immune-marker appeared to only stain a subset of the monocytic/histiocytic cell lineage in rabbits, as evident when applied on spleen sections. There was no histological evidence of mature plasma cells in any of the CNS sections examined. Due to the lack of rabbit-specific or crossreactive antibodies, the remaining population of infiltrating mononuclear leukocytes could not be phenotypically identified at this point in time.

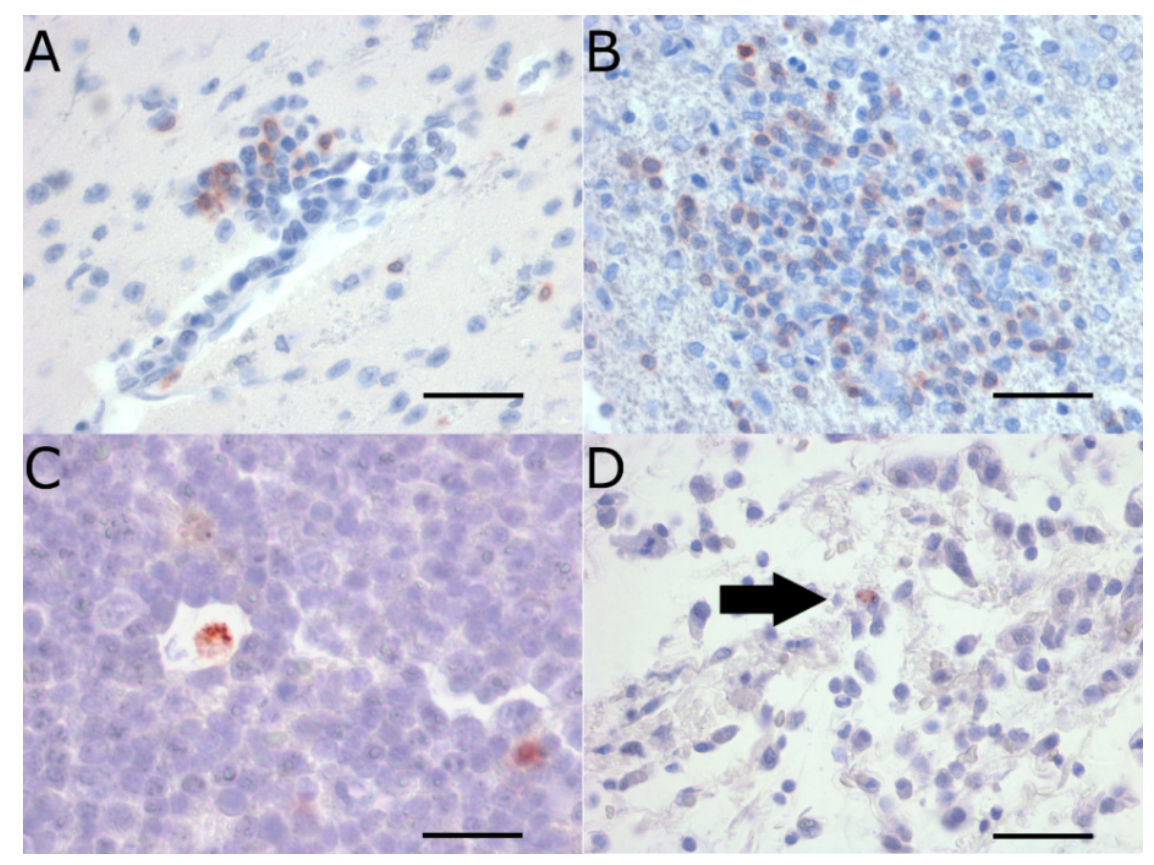

Figure 2. $\mathrm{CD} 3+\mathrm{T}$ cells in the brain $(\mathbf{A}, \mathbf{B})$, and viral NS1 antigen in the draining popliteal lymph node (PLN) (C) and dermis (D). CD3+ T lymphocytes (red stain) infiltrating from cerebral blood vessel (A) in a NZWR infected with WNV $\mathrm{NSW}_{2011}$ on day 7 pi, and in neuropil of brain of a NZWR infected with $\operatorname{MVE}_{1-51}$ (B); Flavivirus NS1 antigen positive leukocyte (red strain) in the paracortical zone of the draining PLN (C); Arrow in panel (D) indicates viral NS1 staining in an individual leukocyte in the deep interstitium of the footpad dermis, ipsilateral to inoculation (D); Panels (A-D) were stained with AEC substrate and counterstained with Meyer's hematoxylin. Magnifications: (A) 40×, (B) 40×, (C) 40× cropped, and (D) 40×. Scale bar in each panel represents $30 \mu \mathrm{m}(\mathbf{A}, \mathbf{B}, \mathbf{D})$ and $20 \mu \mathrm{m}(\mathbf{C})$.

\subsection{Extraneural Pathology}

Lymphocyte activation, as suggested by formation of secondary follicles, paracortical hyperplasia, hypercellularity of the medulla, and hypertrophy of post-capillary endothelial venules, was observed 
commonly in the draining PLN on day 3 and 7 pi for rabbits infected with the three strains of flaviviruses (Table S1). Activation of the contralateral PLN was also occasionally observed in weanling NZWRs (WNVNSW2011: $n=1 / 2$ examined on day 7 pi; MVE1-51: $n=1 / 3$ examined on day 7 pi), but not in adult rabbits on day 7 pi. Notably, all examined contralateral PLNs of CTRs infected with either strain of WNV were activated to varying degree (WNVNSW2011 and WNVTX8667: $n=2 / 2$ on day 3 pi, $n=3 / 3$ on day 7 pi). Where present, there was mild to moderate activation of most tracheobronchial lymph nodes examined, regardless of virus challenge groups. The bronchus-associated lymphoid tissues were also observed to be mildly activated in WNVNSW2011 infected weanling NZWRs on day 7 pi $(n=3 / 3)$.

Major organs were also examined for histopathological lesions in a subset of rabbits from each virus challenge group. Mild focal to multifocal lymphohistiocytic myocarditis with or without epi- and endocarditis was consistently observed in rabbits infected with $\mathrm{WNV}_{\mathrm{NSW} 2011}$ on day 7 pi (Figure $1 \mathrm{D}, n=6 / 6$ weanling NZWRs, $\mathrm{n}=1 / 3$ adult NZWRs and $n=3 / 3$ CTRs) and occasionally in animals infected with $\operatorname{MVE}_{1-51}(n=1 / 3$ weanling and $n=1 / 3$ adult NZWRs) and WNVTX8667 ( $n=1 / 3$ of CTRs). All other organs examined (lungs, kidneys, liver, adrenals, thymus, and eyes) were histologically unremarkable.

\subsection{Viral Burden in the CNS}

Despite the induction of neuropathology, no infectious virus, viral protein, or viral RNA was detected in the brains of NZWRs and CTRs infected with WNV NSW2011. Similar absence of infectious virus was noted in the brains of CTRs infected with WNVTX8667. Only trace levels of MVE1-51 viral RNA were detected in 4/7 of brains that had an encephalitis score of 2 or more ( $n=4 / 12$ tested, median: 22 -fold [increase in viral burden over control], interquartile range [IQR]: 5-43). This suggests a potential correlation between the degree of brain viral load and the degree of neuropathology. Amongst the MVE151 positive brains, two were harvested on day $7 \mathrm{pi}$, one on day $12 \mathrm{pi}$, and one on day 18 pi. However, virus isolation and/or immunohistochemistry failed to detect infectious virus or viral protein from these viral RNA positive brains.

\subsection{Peripheral Virus Replication}

The main site of peripheral replication of $\mathrm{WNV}_{\mathrm{NSW}} 2011$ and $\mathrm{MVE}_{1-51}$ in weanling NZWRs appeared to be the draining PLN. From day 3 to 12 pi, viral RNA was detected in this lymph node, with peak

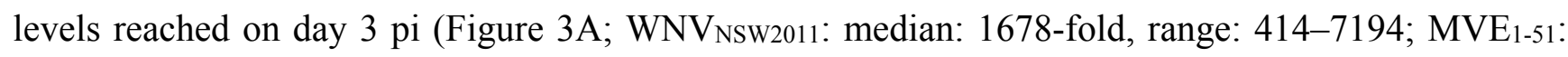
median: 3666-fold, range: 1121-7750). This peak was significantly higher than levels detected on day 12 (WNV NSW2011: $p=0.0082$; MVE $1-51: p=0.0008)$ and 18 pi $\left(\mathrm{WNV}_{\mathrm{NSW}} 2011: p<0.0001\right.$ MVE$_{1-51}$ : $p<0.0001)$. For the MVE $1-51$ group, the day 7 pi viral burden was also significantly higher than on day $12(p=0.0433)$ and 18 pi $(p=0.0041)$. By day 18 pi, viral RNA level was mostly below the detection limit. The overall viral burden in this lymph node was not significantly different between these two virus challenge groups $\left(\mathrm{F}_{1,16}=0.8479, p=0.3708\right)$. On day $7 \mathrm{pi}$, the viral burden in the draining PLN of weanling NZWRs was significantly higher than that of adult NZWRs, regardless of flavivirus strain inoculated (Figure 3C, WNVNSW2011: $p=0.0141$; MVE1-51: $p=0.0065$ ). 
A
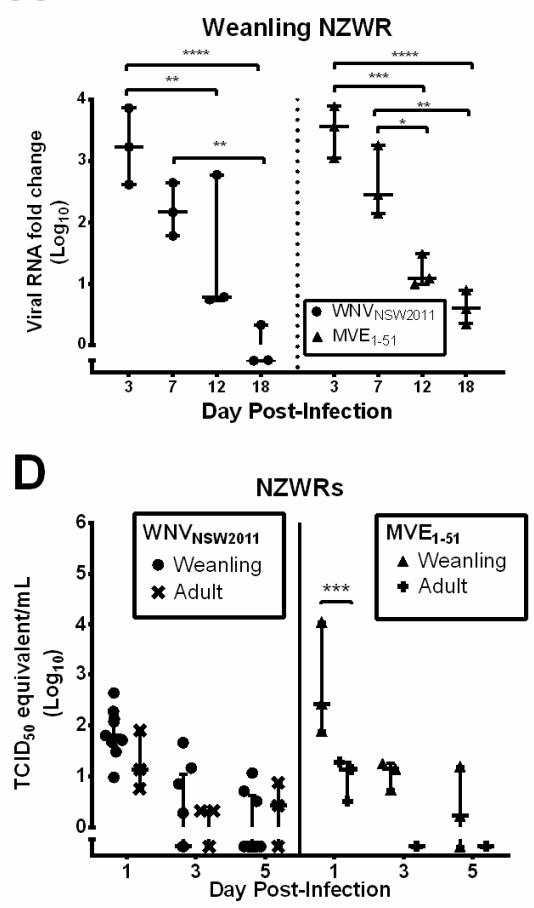

G

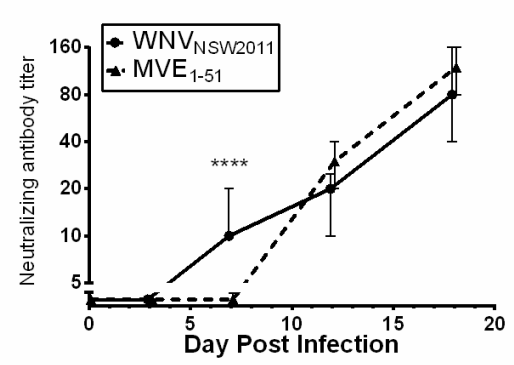

B

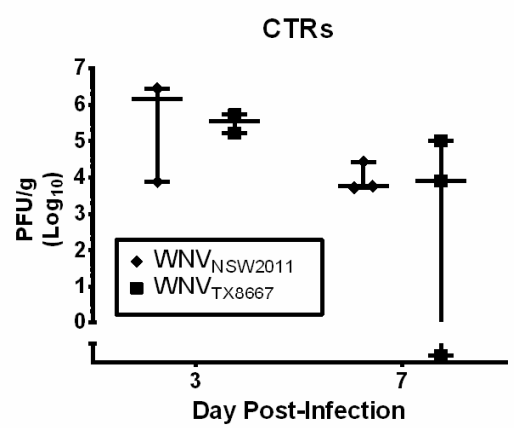

E
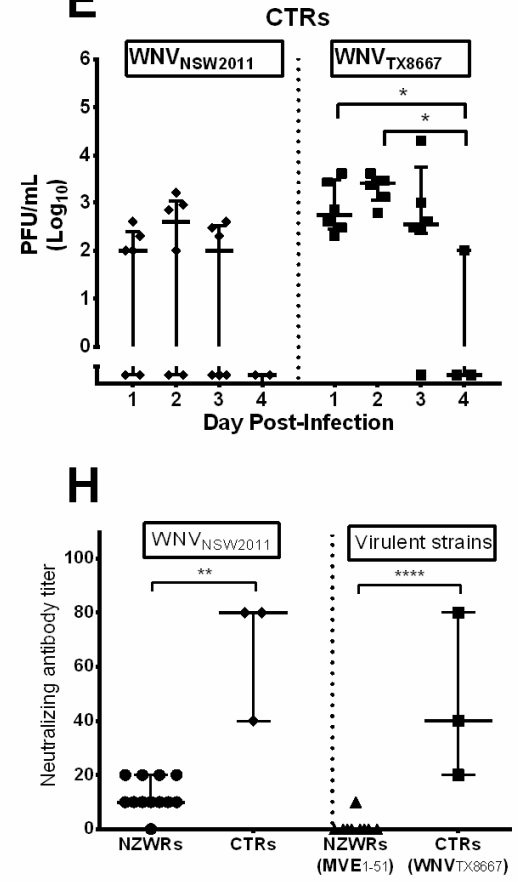

C

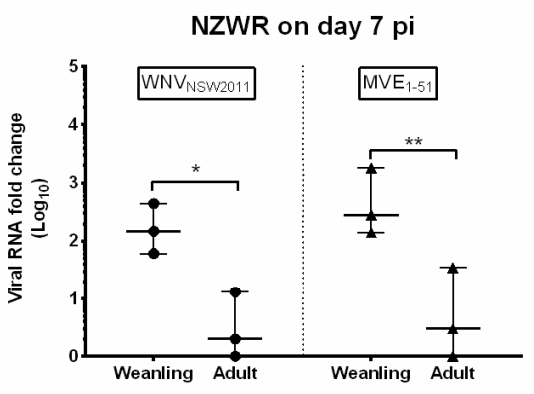

F Weanling NZWR

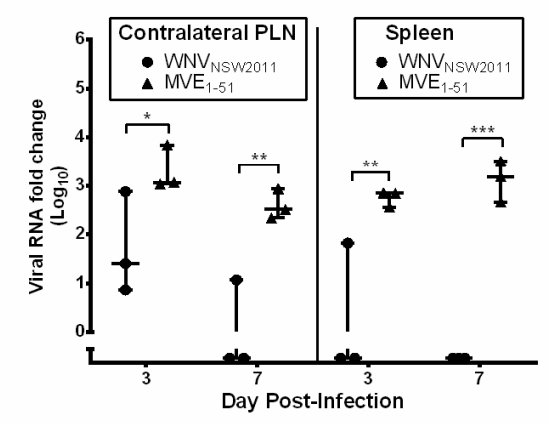

I

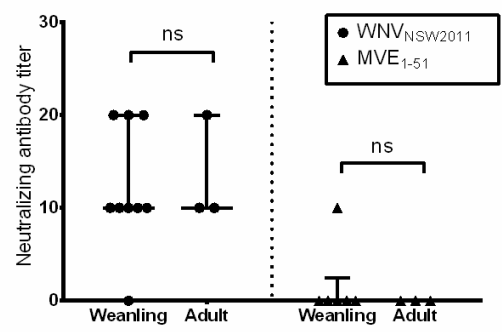

Figure 3. Peripheral virus dissemination and neutralizing antibody response. Viral load in the draining PLN of weanling and adult NZWRs $(\mathbf{A}, \mathbf{C})$ and CTRs $(\mathbf{B})$. Viremia in NZWRs (D) and CTRs (E). Viral burden in the contralateral PLN and spleen (F). Viral RNA in NZWRs was quantified using qRT-PCR, while virus load in CTRs was quantified by plaque assay. Neutralizing antibody kinetics in weanling NZWRs (E), comparison of neutralizing antibody titer between NZWRs and CTRs on day 7 pi (F), and between weanling and adult NZWRs on day 7 pi (I). Note for (F), the NZWR groups include data from both weanling and adult groups to give a closer comparison to the CTR groups. PRNT 90 was used to determine neutralizing antibody titers. Each data point for panels $(\mathbf{A}-\mathbf{F}, \mathbf{H}, \mathbf{I})$ represents titer for one animal. Horizontal line in these panels indicates the median titer of each time-point. For $(\mathbf{E})$, the points on the line indicate the median titer of each time point $(n=3$ for day 3 pi, $6-9$ for day 7 pi and 6 for both day 12 and 18 pi). Error bars indicate the interquartile range or range. Two-way ANOVA with post-test Sidak was performed on the $\log _{10}(\mathrm{Y}+1)$ transformed means of titers in each time-point for panels (A-G,I). One-way ANOVA with post-test Tukey was performed on the $\log _{10}(\mathrm{Y}+1)$ transformed means of titers in each challenge group for panel (H). Statistical significance thresholds: ${ }^{\text {ns }}$ not significant, ${ }^{*} p \leq 0.05,{ }^{*} p \leq 0.01$, $* * * p \leq 0.001, * * * * p \leq 0.0001$. 
Similar kinetics of virus replication in the draining PLN was observed in CTRs infected with the two strains of WNV (Figure 3B). A peak median viral load of $1.4 \times 10^{6}$ (range: $7.6 \times 10^{3}-2.8 \times 10^{6}$ ) and $3.5 \times 10^{5} \mathrm{PFU} / \mathrm{g}$ (range: $1.6 \times 10^{5}-5.3 \times 10^{5}$ ) was reached on day 3 pi for CTRs infected with WNVNSW2011

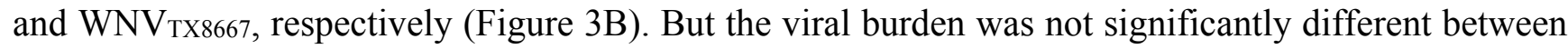
day 3 and 7 pi $\left(F_{1,5}=3.060, p=0.1406\right)$ and between the two virus challenge groups $\left(\mathrm{F}_{1,5}=0.3991\right.$, $p=0.5553)$. Viral RNA assay showed that the amount of WNV $\mathrm{NSW}_{2011} \mathrm{RNA}$ in the draining PLN of WNV NSW2011-infected CTRs was 0.4 and 1.8-fold of that in weanling NZWRs infected with the same virus on day 3 and 7 pi, respectively. This suggests comparable viral burden in the draining PLN between the two species.

Flavivirus NS1 antigen was detected by IHC in pleomorphic leukocytes, suggestive of macrophages and/or dendritic cells, in the paracortical zone of draining PLNs (Figure 2C). Lymph nodes from day 3 pi were more consistently IHC positive for NS1 antigen than on day 7 pi (Table S1). IHC of the footpad, ipsilateral to the inoculation, also revealed NS1 antigen in leukocytes in multiple sites of the deep dermis, in one MVE $1-51$ infected weanling NZWR culled on day 3 pi (Figure 2D). These dermal leukocytes were morphologically consistent with macrophages or dendritic cells.

\subsection{Peripheral Virus Dissemination}

Despite evidence of virus replication in the draining PLN, the associated viremia was transient and of low magnitude for all virus challenge groups (Figure 3D,E). Peak viremia was reached on day 1 pi for weanling (median: 64 TCID 50 equivalent/mL, IQR: 40-162) and adult NZWRs (median: $14 \mathrm{TCID}_{50}$ equivalent/mL, range: 6-80) infected with $\mathrm{WNV}_{\mathrm{NSW}} 2011$ (Figure $3 \mathrm{D}$ ). $\mathrm{MVE}_{1-51}$ infection in weanling NZWRs resulted in a higher median viremia peak at 270 TCID 50 equivalent $/ \mathrm{mL}$ (range: 78-11234) on day 1 pi, which was significantly higher than the median peak of 14 TCID 50 equivalent $/ \mathrm{mL}$ (range: $3-19$ ) reached in the adult group (Figure 3D, $p=0.0063$ ). The overall viremia was significantly different between the two weanling NZWR groups $\left(\mathrm{F}_{1,30}=7.377, p=0.0109\right)$, however, there was no single time-point where a significant difference was observed.

A comparable kinetics of viremia was seen in the WNV-infected CTRs (Figure 3E). Peak viremia occurred on day 2 pi (WNVNSW2011: median: 400 PFU/mL, IQR: 0-1075; WNVTx8667: median: 2600 PFU/mL, IQR: 1125-3225). The overall viremia between these two CTR groups was significantly different $\left(\mathrm{F}_{1.34}=11.28, p=0.0019\right)$. But as for the comparison between the two weanling NZWR groups, there was no single time-point where the difference was significant. For all challenge groups, viremia dropped below the detection limit by day 4 to 5 pi.

The degree of virus replication in other peripheral tissues was limited in WNVNSW2011-infected rabbits. Sites other than the draining PLN where WNV NSw2011 RNA was detected in infected weanling

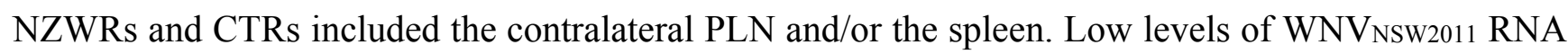
were frequently detected in the contralateral PLN on day 3 pi for NZWR weanlings $(n=3 / 3)$ and CTRs $(n=2 / 3)$. But the viral burden in this lymph node was considerably less than that of the draining PLN (Figure 3F, weanling NZWRs: median: 26-fold, range: 7-750; CTRs: median: 1.6-fold, range: 0-116). It was rare to detect viral RNA in this tissue on day 7 pi (weanling NZWR: $n=1 / 3$, viral burden: 12 fold; adult NZWR: $n=0 / 3$; CTRs: $n=0 / 3$ ). Minimal levels of viral RNA were infrequently detected in

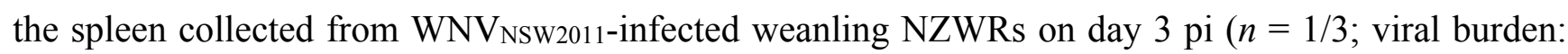


67-fold). No viral RNA was detected in spleen samples from the remaining WNVNSW2011-challenged groups (day 7 pi weanling and adult NZWRs, day 3 and 7 pi CTRs).

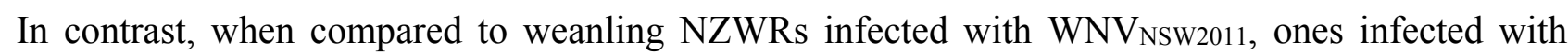
MVE1-51 had significantly higher levels of viral RNA in the contralateral PLN (Figure 3F, day 3 pi: median: 1152-fold, range: 1075-7033, $p=0.0384$; day 7 pi: median: 324-fold, range: 217-867, $p=0.0066$ ) and spleen (Figure 3F, day 3 pi, median: 690 -fold, range: $362-704, p=0.0037$ and day 7 pi: median: 1531 , range: $461-3236, p=0.0003)$. There was also infrequent detectable MVE1-51 RNA in the contralateral PLN ( $n=1 / 3,644$-fold) and spleen of MVE1-51 infected adult NZWRs $(n=1 / 3$, 41-fold), showing a higher capacity for $\mathrm{MVE}_{1-51}$ to disseminate to other lymphoid tissues in both age groups of NZWRs.

\subsection{Neutralizing Antibody Response}

In order to study the potential host factors restricting viremia, the virus-neutralizing antibody response was measured using a plaque reduction neutralization test (PRNT90). A pan-specific flavivirus blocking ELISA was also performed as described [19], with detection of flavivirus specific antibodies in both weanling and adult NZWR MVE1-51 challenged groups. An increasing titer of neutralizing antibodies against the inoculated virus was detected, beginning on day 7 and 12 pi for WNVNSW2011- and MVE1-51- challenged weanling NZWRs, respectively (Figure 3G). The overall neutralizing antibody titers between the two weanling NZWR groups was not significantly different to each other $\left(\mathrm{F}_{1,8}=2.425\right.$, $p=0.1253$ ); however, the titers reached on day 7 pi for WNVNSW2011-challenged weanling NZWRs (median: 10, IQR: 10-20) was significantly higher than those observed in MVE $1-51$ challenged weanling NZWRs (median: 0, IQR: 0-2.5, $p<0.0001$ ). The neutralizing antibody titers in the adult NZWR groups on day 7 pi (WNV NSw2011: median: 10, IQR: 10-20; MVE1-51: median: 0, IQR: 0-0) were comparable to those in the weanlings challenged with the corresponding virus (Figure 3I, $\mathrm{F}_{1,17}=0.02651, p=0.8726$ ). Notably, neutralizing antibody titers in WNVNSw2011-challenged CTRs were significantly higher than those in WNV NSw2011-challenged NZWRs on day 7 pi (Figure 3H; CTR median: 80, IQR: 40-80, $p=0.0094)$. Titers in CTRs infected with WNVTX8667 were comparable to those in CTRs infected with WNVNSW2011 $(p=0.3748)$. But between the two virulent-virus controls of each rabbit species, CTRs infected with WNV TX8667 had significantly higher neutralizing antibody titers than NZWRs infected with MVE1-51 on day 7 pi (Figure $3 \mathrm{H}, p<0.0001$ ).

\subsection{IFN-I and -II Transcription Levels in the Draining Popliteal Lymph Node and Brain}

Given the general resistance of NZWRs and CTRs to WNV and MVEV challenge and the early neutralizing antibody response consequently observed, the type I and II interferon (IFN-I and -II) responses in the brain and draining PLN were investigated.

Overall, between $\mathrm{WNV}_{\mathrm{NSW} 2011}$ and $\mathrm{MVE}_{1-51}$ infected weanling NZWRs, there was a significant difference in the levels of IFN-I and -II transcription in the brain (Figure 4A,D,G; IFNa: $F_{1,16}=18.6700$, $p=0.0005$; IFN $\beta: \mathrm{F}_{1,16}=9.377, p=0.0074$; IFN $\left.\gamma: \mathrm{F}_{1,16}=8.917, p=0.0087\right)$, but not in the draining PLN (Figure 5A,D,G; IFNa: $\mathrm{F}_{1,15}=0.0094, p=0.9242$; IFN $\beta$ : $\mathrm{F}_{1,14}=0.1487, p=0.7056$; IFN $\left.\gamma: \mathrm{F}_{1,15}=0.9710, p=0.3401\right)$. 

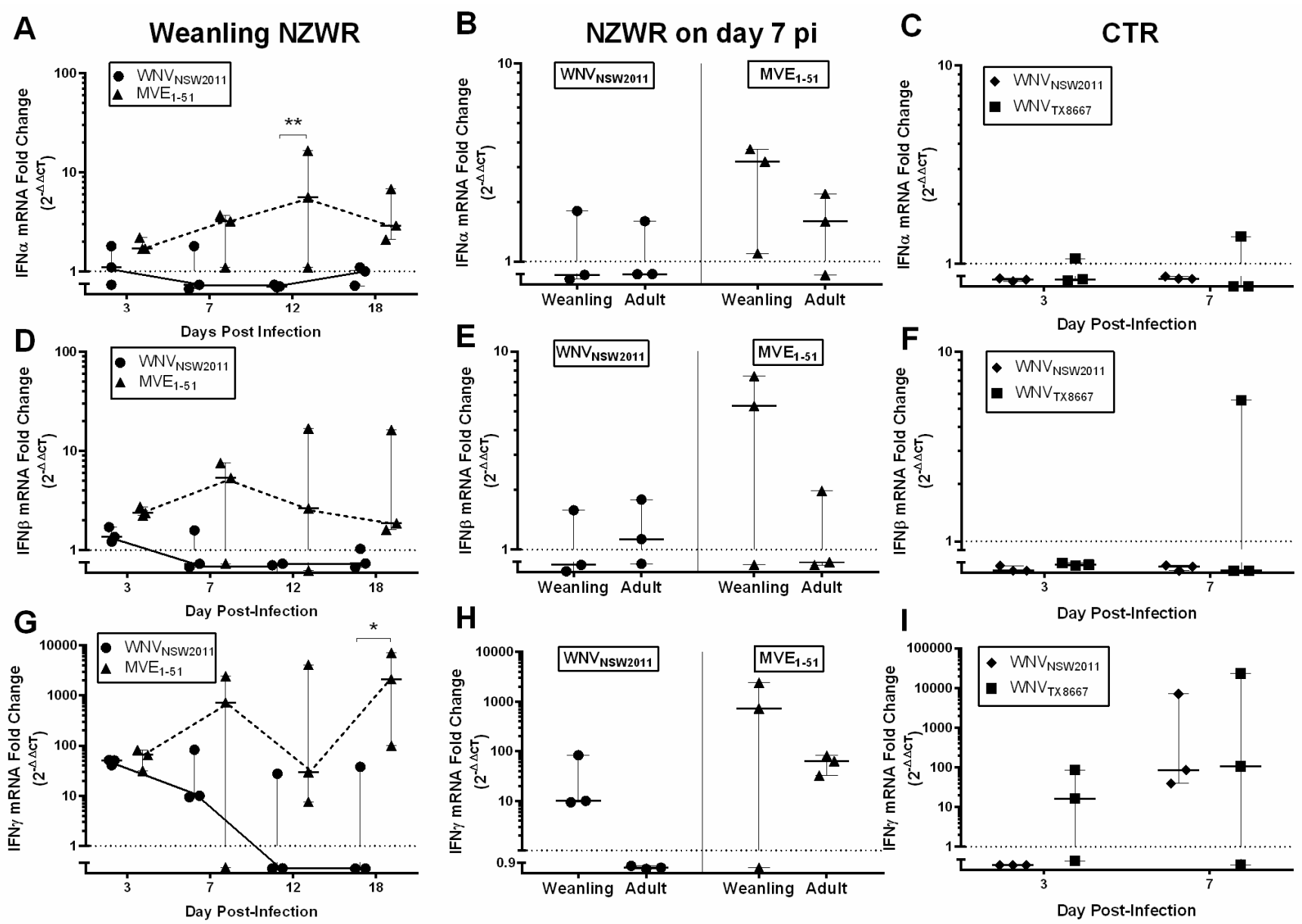

Figure 4. Type I and II IFN transcription kinetics in the brain. IFN $\alpha(\mathbf{A}-\mathbf{C}), \beta(\mathbf{D}-\mathbf{F})$ and $\gamma$ $(\mathbf{G}-\mathbf{I})$ transcription kinetics in the brain of weanling NZWRs $(\mathbf{A}, \mathbf{D}, \mathbf{G})$ and CTRs $(\mathbf{C}, \mathbf{F}, \mathbf{I})$. A comparison of the transcription profile on day 7 pi between weanling and adult NZWRs $(\mathbf{B}, \mathbf{E}, \mathbf{H})$. Each data point represents the fold-change in transcription in one animal. Horizontal solid line in each time-point represents the median fold-change, with error bars indicating the range. Dotted line at $\mathrm{Y}=1$ signifies one-fold (basal level of transcription). Two-way ANOVA with post-test Sidak was performed on the $\log _{10}(\mathrm{Y}+1)$ transformed mean of fold-change in each time-point. Statistical significance thresholds: ${ }^{*} p \leq 0.05$, ** $p \leq 0.01, * * * p \leq 0.001, * * * * p \leq 0.0001$.

IFN $\alpha, \beta$, and $\gamma$ transcription in the brain were comparable between the two groups on day 3 pi, but were quite different from day 7 pi onwards, with brains from MVE1-51-infected weanling NZWRs having consistently upregulated levels of IFN $\alpha, \beta$, and $\gamma$ transcripts (Figure 4A,D,G). In the draining PLN, an earlier upregulation of IFN $\alpha$ (from day 3 pi) and a more consistent upregulation of IFN $\beta$ (from day 7 pi) transcript levels were observed in $\mathrm{WNV}_{\mathrm{NSW}}$ 2011-infected weanling NZWRs, when compared to the $\mathrm{MVE}_{1-51}$ group (Figure 5A,D). The IFN $\gamma$ transcription kinetics in the draining PLN was similar for the two weanling NZWR groups (Figure 5G).

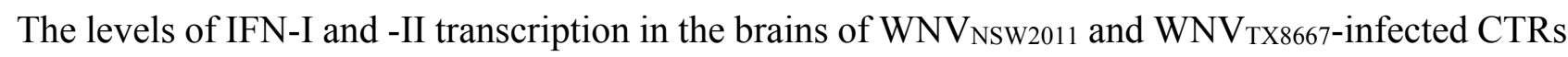
were similar to the profile seen in $\mathrm{WNV}_{\mathrm{NSW} 2011}$ infected weanling NZWRs, where only IFN $\gamma$ mRNA was notably upregulated (Figure 4C,F,I). Upregulation of IFN-I transcription was only observed in brain

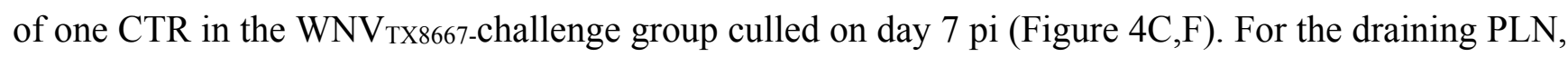


infrequent upregulation of IFN $\alpha$ mRNA was detected on day 7 pi (Figure $5 \mathrm{C}, n=1 / 3$ for both CTR challenge groups). IFN $\beta$ transcription in the draining PLN was consistently upregulated in all three WNV NSW2011-infected CTRs culled on day 7 pi (Figure 5F). Only 1/3 of the WNVTX8667-infected rabbits on day 7 pi had elevated IFN $\beta$ transcription in the draining PLN (Figure 5F). The overall levels of IFN $\gamma$ transcription in the draining PLN in the two CTR groups were comparable to that in the weanling NZWRs (Figure 5G,I). There was no significant effect of age on levels of IFN-I and -II transcription in the brain and draining PLN of NZWRs on day 7 pi, regardless of the virus strain inoculated (Figures 4 and 5B,E,H; brain: IFN $\alpha: \mathrm{F}_{1,8}=0.1719, p=0.6893$; IFN $\beta$ : $\mathrm{F}_{1,8}=0.5947, p=0.4628$; IFN $\gamma$ : $\mathrm{F}_{1,8}=2.215, p=0.1750$; draining PLN: IFNa: $\mathrm{F}_{1,8}=1.839, p=0.2121 ; \operatorname{IFN} \beta: \mathrm{F}_{1,8}=0.4166, p=0.5367$; IFN $\left.\gamma: \mathrm{F}_{1,8}=0.2250, p=0.6479\right)$.
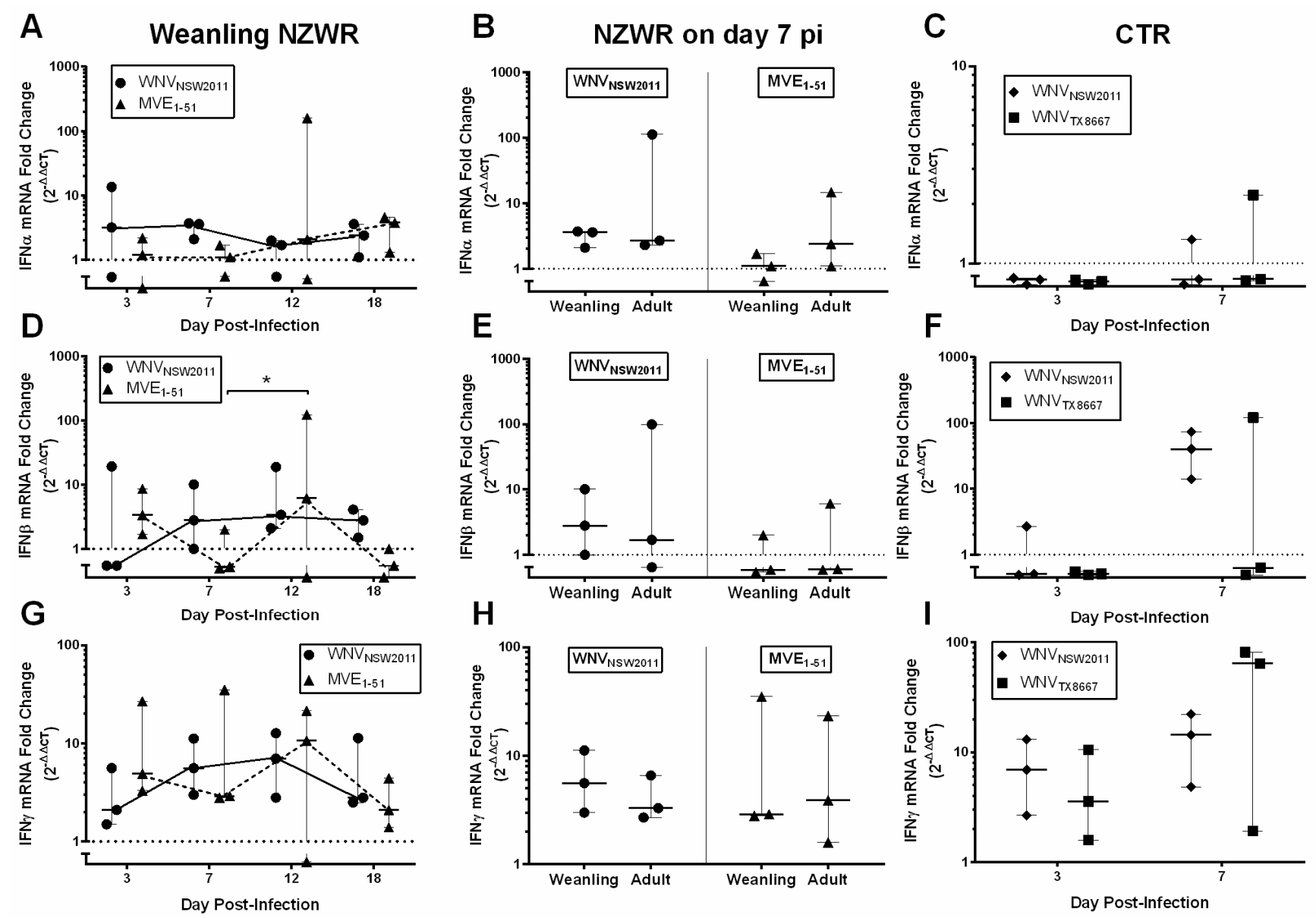

Figure 5. Type I and II IFN transcription kinetics in the draining PLN. IFNa (A-C), $\beta(\mathbf{D}-\mathbf{F})$ and $\gamma(\mathbf{G}-\mathbf{I})$ transcription in the draining politeal lymph node of weanling NZWRs $(\mathbf{A}, \mathbf{D}, \mathbf{G})$ and CTRs $(\mathbf{C}, \mathbf{F}, \mathbf{I})$. A comparison of the transcription profile on day 7 pi between weanling and adult NZWRs $(\mathbf{B}, \mathbf{E}, \mathbf{H})$. Each data point represents the fold-change in transcription in one animal. Horizontal solid line in each time-point represents the median fold-change, with error bars indicating the range. Dotted line at $\mathrm{Y}=1$ signifies one-fold (basal transcription level). Two-way ANOVA with post-test Sidak was performed on the $\log _{10}(\mathrm{Y}+1)$ transformed mean of fold-change in each time-point. Statistical significance thresholds: $* p \leq 0.05, * * p \leq 0.01, * * * p \leq 0.001, * * * * p \leq 0.0001$. 


\section{Discussion}

The current study characterized the clinical, pathological, virological, and immunological outcomes in rabbits after peripheral WNV and MVEV infection. We observed a low-magnitude and transient viremia, similar to that seen in horses, NHPs, and humans [13,20,21]. Peripheral tissue tropism of $\mathrm{WNV}_{\text {NSW2011 }}$ was restricted predominantly to the draining PLN, while MVE1-51 was more successful at disseminating to other lymphoid tissues, such as the contralateral PLN and spleen. However, regardless of the degree of peripheral dissemination, the inoculated virus was mostly undetectable in the brain. The associated early anti-WNV neutralizing antibody production in WNV-infected NZWRs and CTRs was also comparable to that in infected horses and humans [22-24]. This may be explained by the early IFN $\alpha / \beta$ and/or $\gamma$ response in the draining PLN. Our study has also highlighted the importance of the innate immune response in early restriction of virus dissemination, before the appearance of neutralizing antibodies. The resultant mild clinical manifestation and neuropathology in infected rabbits are representative of the non-lethal disease reported for the majority of horse and human WNV infections $[1,2,4,13]$. Immunocompetent rabbits are, therefore, a useful animal model for investigating mechanisms of non-lethal neuropathogenesis and natural means of virus control against virulent WNV and MVEV challenge.

\subsection{Experimental Design}

In this study, we used NZWRs (Oryctolagus cuniculus) and CTRs (Sylvilagus sp.). By including CTRs in this study, we were able to investigate the effect of different rabbit genetic and potential immunological backgrounds on the outcomes of peripheral flavivirus challenge. We also employed the footpad intradermal inoculation route, commonly used in the mouse and hamster models (e.g., [7,8]). This allows appropriate comparison to natural human and equine mosquito bite inoculation. We chose an inoculation dose of $10^{5}$ TCID $_{50}$ (for NZWRs) or PFU (for CTRs) per rabbit, as this is representative of a typical WNV dose delivered by a Culex sp. mosquito bite inoculation [25].

\subsection{Rabbits Can Model Non-Lethal Human and Equine WNV Infections}

The WNV strain of main interest in this study was the Australian equine pathogenic strain, WNVNSW2011 [16]. WNVNSW2011 has previously been shown to be highly virulent in weanling and intermediately virulent in adult CD1 Swiss outbred mice, causing typical neurological signs, such as ataxia, tremor, and seizure prior to death [16]. We have shown in the current study that immunocompetent rabbits do not succumb to inoculation with this strain, regardless of age or species. In fact, even when inoculated with the highly murine-virulent MVE $_{1-51}$ and a virulent North American WNV strain,

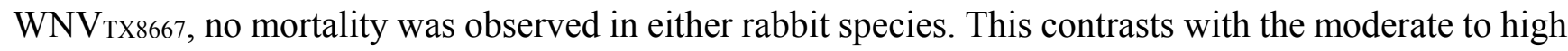
mortality often associated with MVE1-51 and North American lineage I WNV strains in the mouse and hamster model $[7,8,26,27]$. There were also no observable clinical signs, other than a mild to moderate febrile response on day 1 pi in weanling NZWRs. This relatively resistant phenotype in rabbits is representative of the majority of WNV infection in horses and humans $[1,2,4,13]$. Figure 6 summarizes how the NZWR model can be applied to study the different aspects of WNV infections in the humans and horses. 


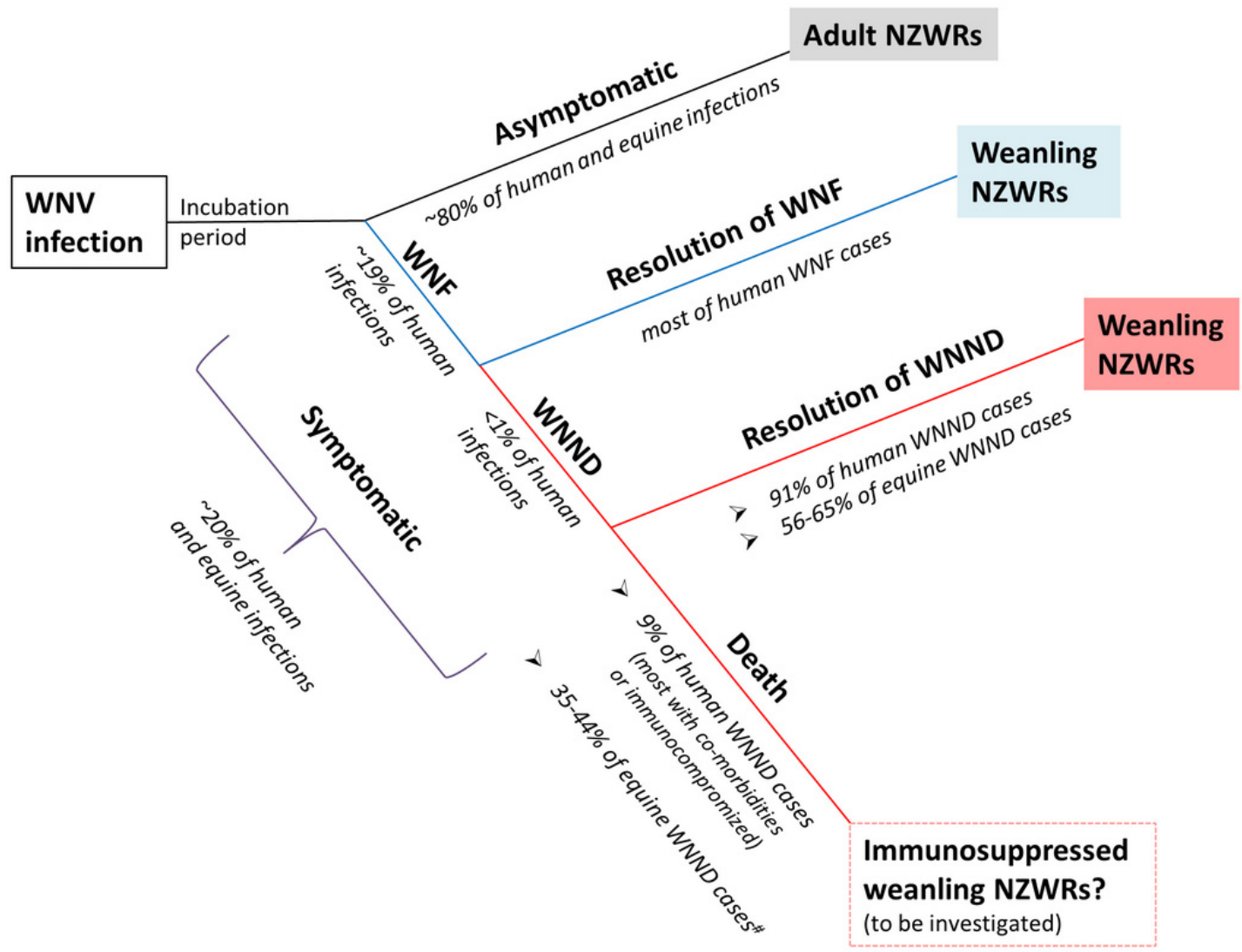

Figure 6. Schematic depiction of how NZWR can model the different aspects of human and equine WNV infections. Our study has shown that WNV-infected NZWRs produce a non-lethal phenotype that is representative of most human and equine infections. The asymptomatic nature of WNV infection in adult NZWRs makes this group of rabbits an appropriate model for determining factors responsible for asymptomatic resolution of human and equine WNV infections. Mild fever was observed in most weanling NZWRs infected with WNV, with some developing mild-moderate non-lethal neuropathology. This group is, therefore, a suitable model for investigating the mechanisms of WNV disease resolution. We also hypothesize that immunosuppression in weanling NZWRs may produce the lethal phenotype typically seen in fatal human and equine WNND cases. Further investigation is required for this particular aspect. This diagram used information obtained from $[1-5,28]$. * the reported equine case-fatality rate does not distinguish between euthanatized cases and natural deaths.

\subsection{Productive Flavivirus Replication in Draining PLN}

Both WNV and MVEV RNA were detected at substantial levels in the draining PLN of weanling NZWRs and CTRs. The detection of flavivirus NS1 antigen in these lymph nodes suggests that productive virus replication occurred in this tissue. Since the draining PLN is the only tissue where viral RNA and antigen were consistently detected across most groups, it may, therefore, be the main site of peripheral virus replication. We identified the permissive cells in these lymph nodes to be pleomorphic leukocytes, consistent with macrophages or dendritic cells in the paracortical zone (Figure 2C). Notably, scant NS1 positive leukocytes were also present in the dermis of a virus-inoculated footpad, suggesting 
that virions have been phagocytosed by leukocytes from the site of inoculation, as suggested in the mouse model $[29,30]$. Productive virus replication also occurred in these leukocytes, since flavivirus NS1 was expressed in these cells. But whether the virus was then transported inside phagocytes to the draining PLN remains to be determined.

There was a notable difference in the draining PLN viral load between the two age groups of NZWRs (Figure 3C). This indicates that adults may be more effective at controlling early peripheral virus replication than weanling NZWRs. This was further supported by the generally low viral burden in all tissues examined, the very mild neuropathology and the afebrile clinical course observed in adults. However, the levels of IFN-I and II transcription in the draining PLN and neutralizing antibody response were not significantly different between these two age groups (Figures 3I, and 5B,E,H). So the mechanisms for this very effective control of virus replication by adult NZWRs remain to be investigated. Characterization of the early immunological events prior to day 3 pi in infected adult and weanling NZWRs will likely shed light on the differences between the two age groups. Nevertheless, due to this benign phenotype, adult NZWRs may be a suitable model for investigating factors determining asymptomatic WNV infections in humans and horses (Figure 6).

\subsection{Restricted Viremia and CNS Infection in Rabbits Resemble Human and Equine WNV Kinetics}

Despite productive infection in the draining PLN, the viremia was low and transient for all virus challenge groups. Interestingly, the viremia peaks observed in our study were lower than those reported in previous flavivirus infection studies in rabbits (peak $\sim 10^{1-3}$ TCID 50 equivalent or PFU/mL, as compared to $\sim 10^{4-5} \mathrm{CID}_{50} / \mathrm{mL}$ or SMIC $\mathrm{LD}_{50} / \mathrm{mL}$ ) [31,32]. This may be explained by the different experimental conditions involved, such as the use of different WNV strains [31], route of inoculation [32], trapping region for CTRs (e.g., Iowa [31]), virus isolation methods (CID50 for [31] and SMIC LD50 for [32]), and a potentially different adult to weaner ratio in recruited wild rabbit groups. Characterization of the effects of the mentioned methodological differences is beyond the scope of the current study, but will be an important aspect for future refinement of the rabbit model.

Nevertheless, the low viremia, restricted peripheral virus dissemination, and CNS infection in WNV-infected rabbits of this study resemble the in vivo virus kinetics reported for experimentally infected NHPs and horses [13,33]. Natural human and equine infections are also commonly associated with minimal to absent neural and extraneural infection [11,12,34]. We, therefore, suggest that the in vivo virus kinetics of WNV in immunocompetent rabbits is similar to that in healthy horses and humans.

\subsection{Weanling NZWRs are an Appropriate Model to Study Non-Fatal Human and Equine WNND}

Despite the lack of or only trace levels of viral RNA in the brain, mild to moderate non-lethal neuropathology was induced in flavivirus-infected rabbits, with animals infected with MVE1-51 and $\mathrm{WNV}_{\text {TX8667 }}$ producing the most frequent and severe lesions (Figure 1A-C). The low case-fatality rate of $9 \%$ from WNND in humans suggests that non-lethal neurological disease is common (91\%) [3]. The equine case-fatality rate of $35-44 \%$ also suggests that approximately half of the symptomatic horses survive WNV infection [5,28]. However, the true survival rate is likely to be higher, since the reported equine case-fatality rate does not distinguish between euthanized cases and natural deaths [5]. This highlights the relatively common occurrence of WNV-induced non-lethal neurological disease in the 
incidental hosts, yet the mechanism of which remains poorly understood. Furthermore, the economic impact of non-lethal WNV-induced disease in human is substantial, highlighting the significance of investigating this important presentation of the disease [6]. The natural development of mild-moderate non-lethal neuropathology mainly in flavivirus-challenged weanling NZWRs suggests that this group of rabbits may be an appropriate model to study the mechanisms of non-lethal neuropathogenesis in horses and humans (Figure 6). Further investigation of the expression kinetics of pro- and anti-inflammatory cytokines in neural and extraneural tissues may provide insights into the mechanisms behind the induction and resolution of neuropathology in flavivirus-infected weanling NZWRs.

\subsection{Virus-Dependent Systemic Virus Dissemination, Peripheral IFN- $\alpha / \beta$, and Neutralizing} Antibody Response

The degree of systemic virus dissemination was virus-dependent in weanling NZWRs. MVE $1-51$ appeared to be more successful in establishing infection in the non-draining PLN and spleen, when compared to $\mathrm{WNV}_{\mathrm{NSW} 2011}$ (Figure $3 \mathrm{~F}$ ). This was not surprising given the higher virulence of MVEV than $\mathrm{WNV}_{\mathrm{NSW}} 2011$ in mice [16,35]. The slower induction of IFNa response in the draining PLN (Figure 5A) and neutralizing antibody production (Figure 3G) in MVE 1 -51-infected weanling NZWRs, relative to ones infected with $\mathrm{WNV}_{\mathrm{NSW} 2011}$, likely have contributed to the more successful peripheral virus dissemination. This association between a delayed peripheral immune response and more profound peripheral virus replication has been reported in mice infected with highly virulent WNV strains, such as WNVKou [9].

However, contrary to the mouse model, weanling NZWRs infected with MVE1-51 did not establish widespread CNS infection. There were trace levels of MVE1-51 RNA in the brain of some of the infected weanling NZWRs. But the elevated and sustained brain IFN-I/II response in MVE1-51-infected weanling NZWRs likely played an important role in local virus control, especially when a delayed peripheral immune response failed to effectively restrict early viral dissemination (Figure 4A,D,G).

Conversely, the faster and more robust IFN $\alpha / \beta$ response in the draining PLN against WNVNSW2011 in weanling NZWRs may explain the limited dissemination of virus to the non-draining PLN and spleen (Figure $3 F$ ). Direct IFN $\alpha / \beta$ restriction on WNV replication, especially for less pathogenic WNV strains, has been well documented [36-38]. However, this faster induction of IFN-I in the draining PLN may also be important for the development of a rapid and effective neutralizing antibody response [39]. In fact, the kinetics of neutralizing antibody production in WNV-infected rabbits mimics very closely that of WNV-infected horses, where PRNT $_{90}$ neutralizing antibody titers of 10 to 80 were reported on day 7 pi [22]. Castillo-Olivares et al. also detected anti-WNV neutralizing antibody $(\sim 100 \%$ neutralization at 1:10 serum dilution) from day 8 pi in experimentally-infected horses [23]. This similarity may also apply to humans, since IgM seroconversion in humans has been estimated to occur around day 7 to 8 post-WNV infection ( $\sim$ days after peak viremia) [24,40]. This early neutralizing antibody production in $\mathrm{WNV}_{\mathrm{NSW} 2011}$ infected weanling NZWRs may have provided adequate peripheral protection against viral neuroinvasion around the crucial time of day 6 to 7 pi, when flavivirus neuroinvasion typically occurs in mice [7]. This may explain the absence of WNV NSW2011 RNA in the brain of these animals. The lack of the continual stimulus in the brain, in turn, corresponds to the lack of upregulated brain IFN $\alpha / \beta$ transcription in these animals. The contrary was observed in MVE ${ }_{1-51}$ infected weanling NZWRs, 
in which the slower neutralizing antibody production may have allowed viral neuroinvasion, which in turn induced a higher and more sustained upregulation of brain IFN $\alpha / \beta$ transcripts (Figure 4A,D).

While we have highlighted the delayed neutralizing antibody production in MVEV-infected NZWRs as a potential reason for the more extensive virus dissemination in the periphery, the previous rabbit study by Kay et al., reported an earlier detection of anti-MVEV neutralizing antibodies (titer of $\sim$ 10-20) in MVEV-infected feral Australian rabbits (Oryctolagus cuniculus) on day 7 pi [32]. However, these feral rabbits may have had a different immunological background to laboratory NZWRs, since co-infection with viruses, bacteria, fungi and/or parasites may have pre-stimulated the immune system in feral rabbits.

\subsection{Neutralizing Antibody and IFNy Response in CTRs}

Evidence of higher neutralizing antibody titers in feral rabbits (CTRs), as compared to laboratory NZWRs, was also observed in the current study (Figure 3H). Since the level of neutralizing antibody production has been reported to be associated with the intensity of IFN $\gamma$ induction in lymph nodes [41], the higher neutralizing antibody production in CTRs may be explained by the marginally higher IFN $\gamma$ transcription in the draining PLNs of the CTRs compared to the NZWRs especially on day 7 pi (Figure 5G,H,I). Furthermore, upregulated IFN $\gamma$ expression in the spleen and the CNS has been reported to be associated with peripheral parasitic infection in mice [42,43]. Potential background parasitic infection in feral CTRs may, therefore, play an important role in shaping the IFN $\gamma$ and the associated neutralizing antibody response in flavivirus-challenged feral rabbits. Wild rabbits may, therefore, be a useful model for investigating the interactions between parasitic and flavivirus co-infection.

\subsection{IFN $\gamma$ Response in NZWRs}

Early upregulated IFN $\gamma$ transcription was also observed in the draining PLN and the brain of most flavivirus-challenged NZWRs (Figures 4 and 5G,H,I). The only exception was in the brain of adult NZWRs infected with WNV $\mathrm{NSW}_{2011}$. This upregulation in IFN $\gamma$ transcripts may have provided early peripheral virus control before a detectable level of neutralizing antibodies began to circulate (prior to day 7 pi for WNV-infected rabbits and prior to day 12 pi for MVE $1-51$ infected rabbits). The suggested mechanism of virus control by IFN $\gamma$ is via its activation of macrophages/dendritic cells/microglial cells $[44,45]$, its support role in establishing a robust CD8 $+\mathrm{T}$ cell response [46], and its role in shaping the antibody response by class switching from IgM to IgG virus neutralizing antibodies [47]. IFN $\gamma$ also has an enhancement role in IFN $\alpha / \beta$ induction via the activation of interferon responsive factor I (IRF-1) [48]. We propose that IFN $\gamma$ may play a key role in: (i) the control of viral load in the draining PLN by its activation of infected macrophages/dendritic cells; (ii) controlling virus infection in the brain by its activation of microglial cells and/or the infiltrated T cells; (iii) forming a competent neutralizing antibody response by class switch; and (iv) co-activation of the IFN-I induction in the draining PLN and brain.

Activated $\mathrm{T}$ lymphocytes, $\gamma \delta \mathrm{T}$ lymphocytes and natural killer (NK) cells have been reported to be the main producers of IFN $\gamma$ [49-51]. It was, therefore, not surprising to observe IFN $\gamma$ transcript upregulation in brains with evidence of CD3 $+\mathrm{T}$ cell infiltration (Figure 2A,B). In fact, CD3+ T cells infiltration into the CNS was a common observation in human, NHP, and equine WNV infections [12,52,53]. 
Furthermore, upregulated IFN $\gamma$ gene transcription in nucleated cells isolated from CSF samples of WNV-infected horses has been reported [54]. This highlights the importance of T lymphocytes and likely the associated IFN $\gamma$ response in virus control in the CNS in incidental hosts and rabbits.

Notably, upregulated IFN $\gamma$ transcription could also be observed in rabbit brains without pathology. While it is possible that rare CNS-infiltrating NK or T cells were not within the histological section examined, a non-leukocyte source(s) of IFN $\gamma$ may be possible. In aged BALB/c mice, expression of IFN $\gamma$ and its receptor has been reported in the cerebral and cerebellar microvascular endothelium, as well as in the choroid plexus [55]. While this did not apply to young adult mice, characterization of such age-related differences has not been performed in rabbits. Furthermore, expression of IFN $\gamma$ and its receptor has been reported in rat sensory neurons grown in culture [56]. These potential non-leukocytic sources of IFN $\gamma$ should be investigated further in our rabbit model by IHC or in situ hybridization for mRNA.

The large variation, as indicated by the large error bars, observed in the rabbits' response against WNV and MVEV infection is likely explained by their outbred background. However, despite this large variation, all rabbits consistently controlled virus replication and survived virus challenge without display of severe clinical signs. This suggests that virus control in outbred rabbits can be achieved at various efficiencies. It is likely that such variability exists in natural human and equine WNV infections, as suggested by the large range of disease outcomes (Figure 6). The outbred rabbit model may, therefore, be a more appropriate tool for delineating the reasons for such variability than the typical inbred mouse models.

\subsection{Significance and Future Directions}

Little is known regarding how virulent flaviviruses induce non-lethal disease and are controlled in naturally resistant hosts. We have presented an alternative small animal model in rabbits for studying WNV-induced non-lethal neuropathogenesis and the natural mechanisms of virus control. We have demonstrated that rabbits, regardless of age or species, are consistently resistant to virulent WNV challenge. As such, rabbits are more suited for investigating mechanisms of virus control than the relatively more susceptible mouse model. Furthermore, this highly resistant phenotype is representative of most human and equine WNV infections. Better understanding of non-lethal neuropathogenesis and resolution of virus infection will help identify key molecules relevant for improving antiviral and therapeutics design for reducing WNV-associated morbidity and mortality in humans and horses. Identification of the factors that determine survival will also help identify novel prognostic indicators for disease progression. As further outbreaks of WNV are expected across the world, non-lethal WNV disease will continue to have great economic impact on global healthcare systems [6,57]. The establishment of the rabbit model presented in this study is, therefore, an important tool for devising ways of ameliorating the impact of WNV on global health.

\section{Materials and Methods}

\subsection{Cell Culture and Virus}

African green monkey (Vero) and Aedes albopictus salivary gland (C6/36) cells were cultured as previously described [9]. Three strains of flaviviruses were used in this study. The isolation, propagation 
and characterization of the equine pathogenic $\mathrm{WNV}_{\mathrm{NSW} 2011}$ outbreak strain and the prototype MVE1-51 have previously been described in details [16,26,58]. An additional passage on C6/36 cells was performed prior to use for inoculation. The North American WNVTX8667 was kindly provided by Robert Tesh, University of Texas Medical Branch (Galveston, TX, USA) and was originally isolated from a bluejay during the 2012 human outbreak in Texas; the virus was passaged once in Vero cells prior to use.

\subsection{Animals and Experimental Design}

Two species of rabbits, the laboratory New Zealand White (NZWR; Oryctolagus cuniculus) and the North American cottontail rabbit (CTR; Sylvilagus sp.), were used in this study. Experimental infection of these two species of rabbits was conducted separately in PC2 and BSL3 animal holding facilities at University of Queensland (UQ), Australia, and Colorado State University (CSU), USA, respectively. Ethical approval was granted from the UQ Animal Ethics Committee (SVS/369/12/ARC) and the CSU Institutional Animal Care and Use Committee (\#14-5170). In total, 57 NZWRs were sourced from Nanowie Small Animal Production Unit (Belbrae, Victoria), while 14 CTRs were trapped in peri-urban areas of Fort Collins, CO, USA. All rabbits used in this study were seronegative by a plaque reduction neutralization test to WNV and MVEV prior to the experimental infection.

The study was divided into three parts: a pilot experiment to explore an age-dependent susceptibility of NZWRs to flavivirus infection, a large scale study to characterize the kinetics of virus infection and pathology, and thirdly, a comparative kinetics study in CTRs. Assignment of rabbits into each virus challenge group is outlined in Table 1. Additionally, six NZWR and two CTR controls were shaminoculated with cell culture media.

For all experiments, a dose of $10^{5}$ TCID 50 (for NZWRs) or PFU (for CTRs) in $50 \mu \mathrm{L}$ of cell culture media was inoculated intradermally in the left hind footpad. Inocula used for the infections were back-titrated and confirmed to be within one $\log _{10}$ of the expected amount. Scheduled euthanasia was performed by overdose with pentobarbitone (Lethabarb, Virbac Animal Health) injection and terminal cardiac bleed.

\subsection{Clinical Monitoring}

A registered veterinarian performed daily clinical monitoring of infected rabbits for signs of malaise and neurological deficit. Measurements of rectal (for NZWRs) or body (for CTRs) temperature, as well as their weights were taken daily. For NZWR rabbits, a standard electronic thermometer was used per rectum. An IPTT300 temperature transponder (BioMedic Data Systems, Inc., Seaford, DE, USA) was implanted subcutaneously in CTRs for daily temperature measurement. The approximate size of both the draining and contralateral PLNs was also gauged by palpation in the NZWR groups. The general alertness, as well as food and water intake, were used as indicators of their well-being. Daily neurological examination by the hopping test was performed on NZWRs to observe for significant loss of coordination of hind and forelimbs [59]. Other neurological signs such as seizures and muscle twitching were monitored. 


\subsection{Tissue Sampling}

From day 1 to 7 pi, blood was collected daily in EDTA-coated or plain collection tubes from the ear vein. Additionally, terminal cardiac bleeds were performed at the time of euthanasia. Collected blood was centrifuged. Plasma/serum was extracted and immediately frozen at $-80^{\circ} \mathrm{C}$ for virus isolation, viral RNA quantitation, and antibody assays.

Following euthanasia, a complete post-mortem examination was performed. Both neural (olfactory bulbs, brain, spinal cord, eyes and sciatic nerves) and extraneural (PLNs, spleen, tracheobronchial lymph nodes, adrenals, kidneys, liver, lungs, heart and thymus) tissues were harvested for one to three of the following assays: histopathological analysis, virus isolation, and viral RNA quantitation.

\subsection{Histopathology}

Samples were fixed in $10 \%$ neutral buffered formalin solution for 48 to $72 \mathrm{~h}$. They were then transferred to $70 \%$ ethanol for storage until routine paraffin embedding was performed. Five micrometer sections were stained with hematoxylin and eosin (H\&E) and examined on a Nikon YS100 light microscrope. Microphotographs were produced as previously described [9]. Histopathological scoring was performed independently by two pathologists, one of whom was blinded to the groups. Specific for the neural tissue, multiple transverse sections of the brain (5-6) and spinal cord (9-10) were examined. The olfactory bulbs and pituitary glands were analyzed and described separately from the rest of the brain. Scores were assigned according to the severity and extensiveness of the lesions. The data presented are the consensus scores between the two pathologists. For neural tissues, the score matrix outline in Table 4 was used.

Table 4. Neuropathology score matrix.

\begin{tabular}{lcccc}
\hline \multirow{4}{*}{ Extensiveness } & & \multicolumn{3}{c}{ SEVERITY } \\
\cline { 2 - 5 } & & Mild & Moderate & Severe \\
\cline { 2 - 5 } & Focal & 1 & 2 & 3 \\
& Multifocal & 2 & 3 & 4 \\
& Diffuse & 3 & 4 & 5 \\
\hline
\end{tabular}

For lymphoid tissues, such as lymph nodes and spleen, a three-tiered scoring system was used to gauge the level of immunological activation, with a score of 3 indicating the most pronounced activation.

\subsection{Immunohistochemistry (IHC)}

Immunolabeling for flaviviral NS1 antigen has been previously described in detail [9]. Immunophenotyping of rabbit $\mathrm{T}$ lymphocytes and histiocytes in inflammatory aggregates was achieved using cross-reactive anti-human CD3 (CD3 clone F7.2.38, Dako) and anti-human myeloid/histiocytic antigen (Clone MAC387, Dako) mouse monoclonal antibodies, respectively, using previously described protocols [60]. For each IHC batch, a positive and negative antigen control was included. 


\subsection{Virus Isolation and Titration}

For NZWR samples, virus isolation and titration was determined by $50 \%$ endpoint of tissue culture infective dose $\left(\mathrm{TCID}_{50}\right.$ ) [9]. Ten-fold serial dilution in 2\% FBS-DMEM of sera or $10 \% \mathrm{w} / \mathrm{v}$ tissue homogenates was performed [9]. Preparation of homogenates has been previously described [9]. Fifty $\mu \mathrm{L}$ of each dilution was added to a subconfluent monolayer of Vero cells in each well of a 96-well tissue culture plate (Costar, Corning). Six to ten replicate wells were used per dilution. The plates were incubated in a $37{ }^{\circ} \mathrm{C}$ incubator at $5 \% \mathrm{CO}_{2}$ for 5 days, before fixation with $20 \%$ acetone (supplemented with $0.02 \% \mathrm{BSA}$ ) for $12-24 \mathrm{~h}$ at $4{ }^{\circ} \mathrm{C}$. Immunocytochemistry was performed on fixed cells, which involved blocking buffer incubated for one hour, anti-flavivirus E protein monoclonal antibody, 4G2, incubated for one hour [61], and HRP-conjugated goat-anti-mouse antibody incubated for 30 minutes, all at room temperature. Staining of $4 \mathrm{G} 2$ positive Vero cells in each well was achieved using DAB+ substrate (Dako) at 1:50 dilution. Each well was manually examined for positive cells under an inverted light microscope (Olympus LH50A). For each assay, both positive and negative controls confirmed the validity of the results.

For CTR samples, standard plaque assay was performed on ten-fold dilutions of sera and $10 \%$ weight/volume tissue homogenates, previously described in $[13,62]$. Hundred $\mu \mathrm{L}$ of inocula was added to confluent monolayers of Vero cells in 6-well tissue culture plates (Costar, Corning) and incubated for $1-2 \mathrm{~h}$ at $37^{\circ} \mathrm{C}$, before $2 \mathrm{~mL}$ of $0.5 \%$ agarose gel overlay was added to each well. Plates were incubated at $37{ }^{\circ} \mathrm{C} 5 \% \mathrm{CO}_{2}$ for 2 days before $2 \mathrm{~mL}$ of a second gel overlay containing $0.005 \%$ neutral red stain was added to each well. Plaques were read on the third and fourth day pi. In each run, both positive and negative controls confirmed the validity of the results.

\subsection{Serology}

An initial screen for flavivirus specific antibodies was performed on plasma/sera obtained from NZWR rabbits at termination by a 4G2 pan-flavivirus blocking ELISA [63,64].

Specific anti-WNV $\mathrm{NSW}_{2011}$ and MVE1-51 neutralizing antibodies in plasma/sera were assayed for by plaque reduction neutralization test $\left(\mathrm{PRNT}_{90}\right)$ in Vero cell culture, as previously described in $[13,62]$. Plasma/serum concentrations tested were 1:10 to 1:320, diluted in culture media (DMEM). For screening exposure status of pre-inoculated rabbits and control rabbits, only a 1:10 dilution of the plasma/serum was tested. Plasma/serum dilutions were then incubated with equal volume $(100 \mathrm{uL})$ of diluted virus stock for 1 at $37^{\circ} \mathrm{C}$. Hundred $\mu \mathrm{L}$ of the plasma/serum-virus mixture was used to inoculate subconfluent monolayer of Veros cells in each well of a 6-well tissue culture plate (Costar, Corning), as per plaque assay protocol $[13,62]$, with modification of agarose used $(1 \%$ of SeaPlaque, Lonza) and method of plaque visualization (1:40 dilution of neutral red dye (Sigma Aldrich) in sterile PBS, applied over the first gel overlay on day 3 pi). Plaques were counted on the fourth day after inoculation. Concentration of WNVNSW2011 and MVE1-51 inocula was back-titrated at neat, 1:2 and 1:4 dilutions in duplicate wells along with each assay to determine the number of plaque forming units used to incubate with plasma/serum dilutions. Neutralizing antibody titers were determined as the inverse of the last plasma/serum concentration showing $90 \%$ plaque reduction. 


\subsection{RNA Extraction}

Viral/total RNA was extracted from plasma/sera and tissues, using Qiamp viral RNA (Qiagen) and RNeasy lipid tissue RNA extraction kit (Qiagen), respectively. Protocol as outlined by the kit was followed, except for tissue harvested from CTR rabbits. For these samples, Qiazol (Qiagen) was substituted with Trizol (Invitrogen). Tissue was homogenized in $1 \mathrm{~mL}$ of Qiazol or Trizol using an Omnitip homogenizer (Omni) or stainless steel beads with a mixer mill (Retsch, Inc., Newtown, PA, USA), respectively. The remaining steps were performed according to the manufacturer's protocol. Additional DNase I digest in solution was performed on extracted RNA, followed by additional RNA clean up with RNeasy RNA extraction kit (Qiagen). The absence of genomic DNA was confirmed by performing PCR without reverse-transcription on a selection of RNA samples from each extraction batch. Quality and concentration of extracted RNA was determined by Nanodrop 1000 spectrophotometer (Thermo Scientific). RNA samples were kept at $-80^{\circ} \mathrm{C}$.

\subsection{Viral RNA Quantitation ( $q R T-P C R)$}

Quantitative reverse-transcriptase PCR (qRT-PCR) was used for viral RNA quantitation. Two $\mu \mathrm{L}$ of RNA template was added in an optimized $15 \mu \mathrm{L}$ reaction, using the one-step Rotor Gene SYBR green RT-PCR kit (Qiagen). Primers targeting $\mathrm{WNV}_{\mathrm{KUN}}$ and $\mathrm{MVE}_{1-51}$ specific NS5 [65] were used at $0.25 \mu \mathrm{M}$ of the final PCR reaction volume. Concentrations of the remaining reagents were used as recommended by the kit. Rotor gene 6000 platform (Qiagen) was used for qRT-PCR amplification. Optimized cycling conditions for the $\mathrm{WNV}_{\mathrm{NSW} 2011}$ assay involved reverse transcription at $55^{\circ} \mathrm{C}$ for $10 \mathrm{~min}$, then PCR initial activation at $95{ }^{\circ} \mathrm{C}$ for $5 \mathrm{~min}$, followed by 45 cycles of $95{ }^{\circ} \mathrm{C}$ for $5 \mathrm{~s}, 65^{\circ} \mathrm{C}$ for $10 \mathrm{~s}$ and $72{ }^{\circ} \mathrm{C}$ for $5 \mathrm{~s}$. The MVE1-51 assay cycling conditions were identical to that of $\mathrm{WNV}_{\mathrm{NSW}} 2011$, except the annealing temperature was $60^{\circ} \mathrm{C}$ [65]. Standard melt curve analysis was performed at the end of each run to check for appropriate qRT-PCR amplification. Standard curve was also generated for both WNV and MVEV assays by serial dilutions of extracted RNA from previously titrated virus stock, similar to method described by Lanciotti et al. [66]. Minimal difference was detected when standard curve was generated from RNA extracted from previously diluted virus stock in control plasma.

In each run, three biological replicates of plasma/serum or tissue sample per time-point, no template control, uninfected tissue controls, and viral RNA positive controls were included. The viral RNA titer in plasma/sera was expressed as TCID 50 equivalent $/ \mathrm{mL}$. For tissue viral load, normalization of viral RNA CT was performed first against the housekeeping gene glyceraldehyde 3-phosphate dehydrogenase (GAPDH), primers for which have been published in [67]. The $2^{-\Delta \Delta C T}$ method was used to quantify tissue viral load relative to background fluorescence from sham-infected controls $[68,69]$. This relative viral burden was expressed as fold increase over sham-infected controls. Limit of detection of both the WNV and MVEV assays was around 29 and 6 TCID 50 equivalent $/ \mathrm{mL}$, as determined by limiting serial 10-fold dilutions.

\subsection{Cytokine Transcription Profiling Assay (RT-qPCR)}

IFN $\alpha, \beta$, and $\gamma$ transcription profiling was performed by two-step RT-qPCR. Two $\mu \mathrm{L}$ of RNA was used in a $20 \mu \mathrm{L}$ qScript first strand synthesis reaction (Quanta Bioscience), which consists of $4 \mu \mathrm{L}$ of 
qScript reaction mix $(5 \times)$ containing a mix of oligo-dT and random primers, and $1 \mu \mathrm{L}$ of qScript reverse transcriptase. The remaining volume was made up by nuclease free water. First strand synthesis reaction was performed on Eppendorf mastercycler epGradient S PCR thermal cycler (Eppendorf), with cycling conditions involving $5 \mathrm{~min}$ of $22{ }^{\circ} \mathrm{C}$ for $5 \mathrm{~min}, 42{ }^{\circ} \mathrm{C}$ for $30 \mathrm{~min}$ and $85^{\circ} \mathrm{C}$ for $5 \mathrm{~min}$. Two $\mu \mathrm{L}$ of cDNA was used in a $20 \mu \mathrm{L}$ Rotor Gene SYBR green PCR reaction (Qiagen); $0.25 \mu \mathrm{M}$ of each forward and reverse primer was used for each reaction. Concentration of the remaining reagents was used as recommended by kit's protocol. IFN $\beta$ and $\gamma$ primers have been previously described in [67]. Primers for IFN $\alpha$ were designed from NCBI reference sequence XM_002708065.1 (IFN $\alpha$-5-like mRNA) using primer design software, Primer 3 plus. IFNa forward primer sequence is 5'-TGCTTGCAGGACAGACATGA-3' and reverse primer sequence is 5'-ATCTCTGTGCTCCACGAGAT-3'. Validation of this primer pair was performed with gel electrophoresis of qPCR products to confirm the 95 base-pair long amplicons. Rotor Gene 6000 platform was used for qPCR amplification with a common cycling conditions for all primer sets, which involves a PCR initial activation step of $95^{\circ} \mathrm{C}$ for $5 \mathrm{~min}$, followed by 40 cycles of $95{ }^{\circ} \mathrm{C}$ for $5 \mathrm{~s}, 60^{\circ} \mathrm{C}$ for $10 \mathrm{~s}$ and $72{ }^{\circ} \mathrm{C}$ for $5 \mathrm{~s}$. Standard melt curve analysis was performed at the end of each run to confirm appropriate PCR amplification. In each run, one cytokine mRNA positive control, generated from concanavalin A (Sigma Aldrich) challenged ex vivo rabbit splenocyte culture, was used. No template control, as well as control tissue samples from sham-inoculated rabbits, was included in each run. Cytokine transcription in sample was normalized to that of the house-keeping gene GAPDH $\left(\Delta \mathrm{CT}_{1}\right)$ [67], and then calibrated to the normalized basal transcription in sham-inoculated control animals $\left(\Delta \mathrm{CT}_{2}\right)$. The $2^{-\Delta \Delta \mathrm{CT}}$ method was then used to calculate the relative fold change in transcription of each sample over that of the controls [68].

\subsection{Statistical Analysis}

Clinical parameters, such as rectal temperature, were normally distributed. Virus titers from various tissues and sera/plasma, as well as antibody titers and cytokine transcription fold-change, were $\log _{10}(\mathrm{Y}+1)$ transformed in order to establish normal distribution. A two-way ANOVA with post-hoc multiple comparisons was performed on these data, in order to assess the effect of time, inoculated virus strain, age, and species of rabbits on the measurements mentioned above. $p$-values have been adjusted for multiple comparisons by either the Tukey or the Sidak method. One-way ANOVA or unpaired t-test with Welch's correction was performed as appropriate. Fisher's exact test was used to compare proportions of animals in each group with pathology. All statistical analyses were performed in statistical software, Graphpad Prism 6.

\section{Conclusions}

The use of the mouse and hamster model for studying host control of virulent WNV infections is limited by their propensity to developing lethal CNS infection. Furthermore, most human and equine WNV infections are not fatal, highlighting the incompatibility of rodents to model the pathogenesis in the incidental hosts. The resistant phenotype induced in WNV-infected rabbits, observed in the current study, is representative of the non-lethal presentation of most human and equine infections. This suggests that rabbits are an appropriate alternative model for studying the induction and resolution of WNV-associated disease. As further outbreaks of WNV are anticipated globally, better understanding 
of the mechanisms of virus control is required, in order to identify novel prognostic indicators, and improve therapeutic and preventative strategies. The current study has, therefore, laid the foundation for addressing this important gap in knowledge.

\section{Supplementary Information}

Supplementary information can be accessed at: http://www.mdpi.com/2076-0817/4/3/529/s1.

\section{Acknowledgments}

This project was supported by an Australian Research Council Linkage Project grant (LP120100686; RAH, HBO), the William Peter Richards Trust Bequest for Veterinary Pathology Research (\#607786; WWS), an Australian Postgraduate Award (WWS), a University of Queensland Graduate School International Travel Award (WWS), and a University of Queensland Postdoctoral Research Fellowship (MJU).

We would also like to thank Robert Tesh for providing the WNVTX8667 strain for the CTR challenge experiment.

\section{Author Contributions}

Willy W. Suen, Natalie A. Prow, Richard A. Bowen, Roy A. Hall, and Helle Bielefeldt-Ohmann conceived and designed the experiments. Willy W. Suen, Muhammad J. Uddin, Wenqi Wang, Vienna Brown, Danielle R. Adney, Nicole Broad, Richard A. Bowen, and Helle Bielefeldt-Ohmann performed the experiments. Willy W. Suen, Muhammad J. Uddin, Wenqi Wang, Natalie A. Prow, Roy A. Hall, and Helle Bielefeldt-Ohmann analyzed the data. Willy W. Suen, Muhammad J. Uddin, Richard A. Bowen, Roy A. Hall, and Helle Bielefeldt-Ohmann contributed reagents/materials/analysis tools. Willy W. Suen and Helle Bielefeldt-Ohmann wrote the paper. All authors contributed to revisions and approved the final submission.

\section{Conflicts of Interest}

The authors declare no conflict of interest.

\section{References}

1. Mostashari, F.; Bunning, M.L.; Kitsutani, P.T.; Singer, D.A.; Nash, D.; Cooper, M.J.; Katz, N.; Liljebjelke, K.A.; Biggerstaff, B.J.; Fine, A.D.; et al. Epidemic west nile encephalitis, new york, 1999: Results of a household-based seroepidemiological survey. Lancet 2001, 358, 261-264.

2. Zou, S.; Foster, G.A.; Dodd, R.Y.; Petersen, L.R.; Stramer, S.L. West nile fever characteristics among viremic persons identified through blood donor screening. J. Infect. Dis. 2010, 202, 1354-1361.

3. Lindsey, N.P.; Staples, J.E.; Lehman, J.A.; Fischer, M. Surveillance for human west nile virus disease-United states, 1999-2008. MMWR Surveill. Summ. 2010, 59, 1-17. 
4. Nielsen, C.F.; Reisen, W.K.; Armijos, M.V.; Maclachlan, N.J.; Scott, T.W. High subclinical west nile virus incidence among nonvaccinated horses in northern california associated with low vector abundance and infection. Am. J. Trop. Med. Hyg. 2008, 78, 45-52.

5. Ostlund, E.N.; Crom, R.L.; Pedersen, D.D.; Johnson, D.J.; Williams, W.O.; Schmitt, B.J. Equine west nile encephalitis, united states. Emerg. Infect. Dis. 2001, 7, 665-669.

6. Nolan, M.S.; Schuermann, J.; Murray, K.O. West nile virus infection among humans, texas, USA, 2002-2011. Emerg. Infect. Dis. 2013, 19, 137-139.

7. Diamond, M.S.; Shrestha, B.; Marri, A.; Mahan, D.; Engle, M. B cells and antibody play critical roles in the immediate defense of disseminated infection by west nile encephalitis virus. J. Virol. 2003, 77, 2578-2586.

8. Xiao, S.Y.; Guzman, H.; Zhang, H.; Travassos da Rosa, A.P.; Tesh, R.B. West nile virus infection in the golden hamster (mesocricetus auratus): A model for west nile encephalitis. Emerg. Infect. Dis. 2001, 7, 714-721.

9. Prow, N.A.; Setoh, Y.X.; Biron, R.M.; Sester, D.P.; Kim, K.S.; Hobson-Peters, J.; Hall, R.A.; Bielefeldt-Ohmann, H. The west nile-like flavivirus koutango is highly virulent in mice due to delayed viral clearance and the induction of a poor neutralizing antibody response. J. Virol. 2014, 188, 9947-9962.

10. Suen, W.W.; Prow, N.A.; Hall, R.A.; Bielefeldt-Ohmann, H. Mechanism of west nile virus neuroinvasion: A critical appraisal. Viruses 2014, 6, 2796-2825.

11. Guarner, J.; Shieh, W.J.; Hunter, S.; Paddock, C.D.; Morken, T.; Campbell, G.L.; Marfin, A.A.; Zaki, S.R. Clinicopathologic study and laboratory diagnosis of 23 cases with west nile virus encephalomyelitis. Hum. Pathol. 2004, 35, 983-990.

12. Cantile, C.; Del Piero, F.; di Guardo, G.; Arispici, M. Pathologic and immunohistochemical findings in naturally occuring west nile virus infection in horses. Vet. Pathol. 2001, 38, 414-421.

13. Bunning, M.L.; Bowen, R.A.; Cropp, C.B.; Sullivan, K.G.; Davis, B.S.; Komar, N.; Godsey, M.S.; Baker, D.; Hettler, D.L.; Holmes, D.A.; et al. Experimental infection of horses with west nile virus. Emerg. Infect. Dis. 2002, 8, 380-386.

14. Kumar, M.; O’Connell, M.; Namekar, M.; Nerurkar, V.R. Infection with non-lethal west nile virus eg101 strain induces immunity that protects mice against the lethal west nile virus ny99 strain. Viruses 2014, 6, 2328-2339.

15. Shirato, K.; Kimura, T.; Mizutani, T.; Kariwa, H.; Takashima, I. Different chemokine expression in lethal and non-lethal murine west nile virus infection. $J$. Med. Virol. 2004, 74, 507-513.

16. Frost, M.J.; Zhang, J.; Edmonds, J.H.; Prow, N.A.; Gu, X.; Davis, R.; Hornitzky, C.; Arzey, K.E.; Finlaison, D.; Hick, P.; et al. Characterization of virulent west nile virus kunjin strain, australia, 2011. Emerg. Infect. Dis. 2012, 18, 792-800.

17. Venter, M.; Human, S.; Zaayman, D.; Gerdes, G.H.; Williams, J.; Steyl, J.; Leman, P.A.; Paweska, J.T.; Setzkorn, H.; Rous, G.; et al. Lineage 2 west nile virus as cause of fatal neurologic disease in horses, south africa. Emerg. Infect. Dis. 2009, 15, 877-884.

18. Lobigs, M.; Marshall, I.D.; Weir, R.C.; Dalgarno, L. Genetic differentiation of murray valley encephalitis virus in australia and papua new guinea. Aust. J. Exp. Biol. Med. Sci. 1986, 64, $571-585$. 
19. Blitvich, B.J.; Bowen, R.A.; Marlenee, N.L.; Hall, R.A.; Bunning, M.L.; Beaty, B.J. Epitope-blocking enzyme-linked immunosorbent assays for detection of west nile virus antibodies in domestic mammals. J. Clin. Microbiol. 2003, 41, 2676-2679.

20. Dayan, G.H.; Bevilacqua, J.; Coleman, D.; Buldo, A.; Risi, G. Phase II, dose ranging study of the safety and immunogenicity of single dose west nile vaccine in healthy adults $\geq 50$ years of age. Vaccine 2012, 30, 6656-6664.

21. Ratterree, M.S.; Gutierrez, R.A.; Travassos da Rosa, A.P.; Dille, B.J.; Beasley, D.W.; Bohm, R.P.; Desai, S.M.; Didier, P.J.; Bikenmeyer, L.G.; Dawson, G.J.; et al. Experimental infection of rhesus macaques with west nile virus: Level and duration of viremia and kinetics of the antibody response after infection. J. Infect. Dis. 2004, 189, 669-676.

22. Seino, K.K.; Long, M.T.; Gibbs, E.P.; Bowen, R.A.; Beachboard, S.E.; Humphrey, P.P.; Dixon, M.A.; Bourgeois, M.A. Comparative efficacies of three commercially available vaccines against west nile virus (wnv) in a short-duration challenge trial involving an equine wnv encephalitis model. Clin. Vaccine Immunol. 2007, 14, 1465-1471.

23. Castillo-Olivares, J.; Mansfield, K.L.; Phipps, L.P.; Johnson, N.; Tearle, J.; Fooks, A.R. Antibody response in horses following experimental infection with west nile virus lineages 1 and 2 . Transbound. Emerg. Dis. 2011, 58, 206-212.

24. Busch, M.P.; Kleinman, S.H.; Tobler, L.H.; Kamel, H.T.; Norris, P.J.; Walsh, I.; Matud, J.L.; Prince, H.E.; Lanciotti, R.S.; Wright, D.J.; et al. Virus and antibody dynamics in acute west nile virus infection. J. Infect. Dis. 2008, 198, 984-993.

25. Styer, L.M.; Kent, K.A.; Albright, R.G.; Bennett, C.J.; Kramer, L.D.; Bernard, K.A. Mosquitoes inoculate high doses of west nile virus as they probe and feed on live hosts. PLoS Pathog. 2007, 3 , 1262-1270.

26. Lobigs, M.; Marshall, I.D.; Weir, R.C.; Dalgarno, L. Murray valley encephalitis virus field strains from australia and papua new guinea: Studies on the sequence of the major envelope protein gene and virulence for mice. Virology 1988, 165, 245-255.

27. Brown, A.N.; Kent, K.A.; Bennett, C.J.; Bernard, K.A. Tissue tropism and neuroinvasion of west nile virus do not differ for two mouse strains with different survival rates. Virology 2007, 368, 422-430.

28. Epp, T.; Waldner, C.; West, K.; Townsend, H. Factors associated with west nile virus disease fatalities in horses. Can. Vet. J. 2007, 48, 1137-1145.

29. Byrne, S.N.; Halliday, G.M.; Johnston, L.J.; King, N.J. Interleukin-1beta but not tumor necrosis factor is involved in west nile virus-induced langerhans cell migration from the skin in c57bl/6 mice. J. Investig. Dermatol. 2001, 117, 702-709.

30. Johnston, L.J.; Halliday, G.M.; King, N.J. Langerhans cells migrate to local lymph nodes following cutaneous infection with an arbovirus. J. Investig. Dermatol. 2000, 114, 560-568.

31. Tiawsirisup, S.; Platt, K.B.; Tucker, B.J.; Rowley, W.A. Eastern cottontail rabbits (sylvilagus floridanus) develop west nile virus viremias sufficient for infecting select mosquito species. Vector Borne Zoonotic Dis. 2005, 5, 342-350.

32. Kay, B.H.; Young, P.L.; Hall, R.A.; Fanning, I.D. Experimental infection with murray valley encephalitis virus. Pigs, cattle, sheep, dogs, rabbits, macropods and chickens. Aust. J. Exp. Biol. Med. Sci. 1985, 63, 109-126. 
33. Verstrepen, B.E.; Fagrouch, Z.; van Heteren, M.; Buitendijk, H.; Haaksma, T.; Beenhakker, N.; Palu, G.; Richner, J.M.; Diamond, M.S.; Bogers, W.M.; et al. Experimental infection of rhesus macaques and common marmosets with a european strain of west nile virus. PLoS Negl. Trop. Dis. 2014, 8, e2797.

34. Smith, R.D.; Konoplev, S.; DeCourten-Myers, G.; Brown, T. West nile virus encephalitis with myositis and orchitis. Hum. Pathol. 2004, 35, 254-258.

35. McMinn, P.C.; Dalgarno, L.; Weir, R.C. A comparison of the spread of murray valley encephalitis viruses of high or low neuroinvasiveness in the tissues of swiss mice after peripheral inoculation. Virology 1996, 220, 414-423.

36. Hussmann, K.L.; Samuel, M.A.; Kim, K.S.; Diamond, M.S.; Fredericksen, B.L. Differential replication of pathogenic and nonpathogenic strains of west nile virus within astrocytes. J. Virol. 2013, 87, 2814-2822.

37. Laurent-Rolle, M.; Boer, E.F.; Lubick, K.J.; Wolfinbarger, J.B.; Carmody, A.B.; Rockx, B.; Liu, W.; Ashour, J.; Shupert, W.L.; Holbrook, M.R.; et al. The ns5 protein of the virulent west nile virus ny99 strain is a potent antagonist of type i interferon-mediated jak-stat signaling. J. Virol. 2010, 84, 3503-3515.

38. Keller, B.C.; Fredericksen, B.L.; Samuel, M.A.; Mock, R.E.; Mason, P.W.; Diamond, M.S.; Gale, M., Jr. Resistance to alpha/beta interferon is a determinant of west nile virus replication fitness and virulence. J. Virol. 2006, 80, 9424-9434.

39. Purtha, W.E.; Chachu, K.A.; Virgin, H.W.T.; Diamond, M.S. Early b-cell activation after west nile virus infection requires alpha/beta interferon but not antigen receptor signaling. J. Virol. 2008, 82, 10964-10974.

40. Hayes, E.B.; Sejvar, J.J.; Zaki, S.R.; Lanciotti, R.S.; Bode, A.V.; Campbell, G.L. Virology, pathology, and clinical manifestations of west nile virus disease. Emerg. Infect. Dis. 2005, 11, 1174-1179.

41. Neves, P.C.C.; Santos, J.R.; Tubarão, L.N.; Bonaldo, M.C.; Galler, R. Early ifn-gamma production after yf $17 \mathrm{~d}$ vaccine virus immunization in mice and its association with adaptive immune responses. PLoS ONE 2013, 8, e81953.

42. Lopez-Griego, L.; Nava-Castro, K.E.; Lopez-Salazar, V.; Hernandez-Cervantes, R.; Tiempos Guzman, N.; Muniz-Hernandez, S.; Hernandez-Bello, R.; Besedovsky, H.O.; Pavon, L.; Becerril Villanueva, L.E.; et al. Gender-associated differential expression of cytokines in specific areas of the brain during helminth infection. J. Interferon Cytokine Res. 2015, 35, 116-125.

43. Peng, S.Y.; Chu, T.H.; Wang, I.C.; Chung, W.C.; Yu, K.W.; Tsaihong, J.C.; Huang, J.C.; Fan, P.C. Infection of normal $\mathrm{c} 3 \mathrm{~h} / \mathrm{h}$ en mice with taenia saginata asiatica oncospheres. Res. Vet. Sci. 2009, 86, 261-266.

44. MacMicking, J.; Xie, Q.W.; Nathan, C. Nitric oxide and macrophage function. Annu. Rev. Immunol. 1997, 15, 323-350.

45. Kreutzberg, G.W. Microglia: A sensor for pathological events in the cns. Trends Neurosci. 1996, 19, 312-318.

46. Miller, J.D.; van der Most, R.G.; Akondy, R.S.; Glidewell, J.T.; Albott, S.; Masopust, D.; Murali-Krishna, K.; Mahar, P.L.; Edupuganti, S.; Lalor, S.; et al. Human effector and memory $\operatorname{cd} 8(+) \mathrm{t}$ cell responses to smallpox and yellow fever vaccines. Immunity 2008, 28, 710-722. 
47. Dittmer, U.; Peterson, K.E.; Messer, R.; Stromnes, I.M.; Race, B.; Hasenkrug, K.J. Role of interleukin-4 (il-4), il-12, and gamma interferon in primary and vaccine-primed immune responses to friend retrovirus infection. J. Virol. 2001, 75, 654-660.

48. Liu, S.Y.; Sanchez, D.J.; Aliyari, R.; Lu, S.; Cheng, G. Systematic identification of type i and type ii interferon-induced antiviral factors. Proc. Natl. Acad. Sci. USA 2012, 109, 4239-4244.

49. Girdlestone, J.; Wing, M. Autocrine activation by interferon-gamma of stat factors following t cell activation. Eur. J. Immunol. 1996, 26, 704-709.

50. Christmas, S.E.; Meager, A. Production of interferon-gamma and tumor-necrosis-factor-alpha by human t-cell clones expressing different forms of the gamma-delta-receptor. Immunology 1990, 71, 486-492.

51. Biron, C.A.; Nguyen, K.B.; Pien, G.C.; Cousens, L.P.; Salazar-Mather, T.P. Natural killer cells in antiviral defense: Function and regulation by innate cytokines. Annu. Rev. Immunol. 1999, 17, 189-220.

52. Omalu, B.I.; Shakir, A.A.; Wang, G.; Lipkin, W.I.; Wiley, C.A. Fatal fulminant pan-meningo-polioencephalitis due to west nile virus. Brain Pathol. 2003, 13, 465-472.

53. Maximova, O.A.; Ward, J.M.; Asher, D.M.; St Claire, M.; Finneyfrock, B.W.; Speicher, J.M.; Murphy, B.R.; Pletnev, A.G. Comparative neuropathogenesis and neurovirulence of attenuated flaviviruses in nonhuman primates. $J$. Virol. 2008, 82, 5255-5268.

54. Pusterla, N.; Wilson, W.D.; Conrad, P.A.; Mapes, S.; Leutenegger, C.M. Comparative analysis of cytokine gene expression in cerebrospinal fluid of horses without neurologic signs or with selected neurologic disorders. Am. J. Vet. Res. 2006, 67, 1433-1437.

55. Wei, Y.P.; Kita, M.; Shinmura, K.; Yan, X.Q.; Fukuyama, R.; Fushiki, S.; Imanishi, J. Expression of ifn-gamma in cerebrovascular endothelial cells from aged mice. J. Interferon Cytokine Res. 2000, 20, 403-409.

56. Neumann, H.; Schmidt, H.; Wilharm, E.; Behrens, L.; Wekerle, H. Interferon gamma gene expression in sensory neurons: Evidence for autocrine gene regulation. J. Exp. Med. 1997, 186, 2023-2031.

57. Beasley, D.W.; Barrett, A.D.; Tesh, R.B. Resurgence of west nile neurologic disease in the united states in 2012: What happened? What needs to be done? Antivir. Res. 2013, 99, 1-5.

58. Dalgarno, L.; Trent, D.W.; Strauss, J.H.; Rice, C.M. Partial nucleotide sequence of the murray valley encephalitis virus genome. Comparison of the encoded polypeptides with yellow fever virus structural and non-structural proteins. J. Mol. Biol. 1986, 187, 309-323.

59. Lorenz, M.D.; Coates, J.R.; Kent, M. Handbook of Veterinary Neurology, 5th ed.; Elsevier/Saunders: St. Louis, MI, USA, 2011; p. 28.

60. Tolnay, A.E.; Baskin, C.R.; Tumpey, T.M.; Sabourin, P.J.; Sabourin, C.L.; Long, J.P.; Pyles, J.A.; Albrecht, R.A.; Garcia-Sastre, A.; Katze, M.G.; et al., Extrapulmonary tissue responses in cynomolgus macaques (macaca fascicularis) infected with highly pathogenic avian influenza a (h5n1) virus. Arch. Virol. 2010, 155, 905-914.

61. Hall, R.A.; Kay, B.H.; Burgess, G.W. An enzyme immunoassay to detect australian flaviviruses and identify the encephalitic subgroup using monoclonal antibodies. Immunol. Cell Biol. 1987, 65, $103-110$. 
62. Bowen, R.A.; Rouge, M.M.; Siger, L.; Minke, J.M.; Nordgren, R.; Karaca, K.; Johnson, J. Pathogenesis of west nile virus infection in dogs treated with glucocorticoids. Am. J. Trop. Med. Hyg. 2006, 74, 670-673.

63. Prow, N.A.; Tan, C.S.; Wang, W.; Hobson-Peters, J.; Kidd, L.; Barton, A.; Wright, J.; Hall, R.A.; Bielefeldt-Ohmann, H. Natural exposure of horses to mosquito-borne flaviviruses in south-east queensland, australia. Int. J. Environ. Res. Public. Health 2013, 10, 4432-4443.

64. Prow, N.A.; Hewlett, E.K.; Faddy, H.M.; Coiacetto, F.; Wang, W.; Cox, T.; Hall, R.A.; BielefeldtOhmann, H. The australian public is still vulnerable to emerging virulent strains of west nile virus. Front. Public Health 2014, 2, 146.

65. Pyke, A.T.; Smith, I.L.; van den Hurk, A.F.; Northill, J.A.; Chuan, T.F.; Westacott, A.J.; Smith, G.A. Detection of australasian flavivirus encephalitic viruses using rapid fluorogenic taqman rt-pcr assays. J. Virol. Methods 2004, 117, 161-167.

66. Lanciotti, R.S.; Kerst, A.J.; Nasci, R.S.; Godsey, M.S.; Mitchell, C.J.; Savage, H.M.; Komar, N.; Panella, N.A.; Allen, B.C.; Volpe, K.E.; et al. Rapid detection of west nile virus from human clinical specimens, field-collected mosquitoes, and avian samples by a taqman reverse transcriptase-pcr assay. J. Clin. Microbiol. 2000, 38, 4066-4071.

67. Schnupf, P.; Sansonetti, P.J. Quantitative rt-pcr profiling of the rabbit immune response: Assessment of acute shigella flexneri infection. PLOS ONE 2012, 7, e36446.

68. Pfaffl, M.W. A new mathematical model for relative quantification in real-time rt-pcr. Nucl. Acids Res. 2001, 29, e45.

69. Smirnova, N.P.; Webb, B.T.; Bielefeldt-Ohmann, H.; Van Campen, H.; Antoniazzi, A.Q.; Morarie, S.E.; Hansen, T.R. Development of fetal and placental innate immune responses during establishment of persistent infection with bovine viral diarrhea virus. Virus Res. 2012, 167, 329-336.

(C) 2015 by the authors; licensee MDPI, Basel, Switzerland. This article is an open access article distributed under the terms and conditions of the Creative Commons Attribution license (http://creativecommons.org/licenses/by/4.0/). 